\title{
Interaction between the Postsubiculum and Anterior Thalamus in the Generation of Head Direction Cell Activity
}

\author{
Jeremy P. Goodridge and Jeffrey S. Taube \\ Department of Psychology, Dartmouth College, Hanover, New Hampshire 03755
}

Previous research has identified neurons in the postsubiculum (PoS) and anterior dorsal thalamic nucleus (AD) of the rat that discharge as a function of the animal's head direction. In addition, anatomical studies have shown that the AD and PoS are reciprocally connected with one another. The current study examined whether head direction (HD) cells in each of the two areas is dependent on input from the other structure. After both electrolytic or neurotoxic lesions of the AD, no cells were identified with direction-specific discharge in the PoS. In contrast, AD HD cell activity was still present after neurotoxic lesions to the PoS. However, AD HD cells in PoS-lesioned rats exhibited three important differences compared with AD HD cells in intact animals: (1) their directional firing range was significantly larger, (2) their firing predicted the animal's future head direction by a larger amount, and (3) their preferred firing direction was substantially less influenced by a prominent visual landmark within the recording environment. These results indicate that information critical for HD cell activity is conveyed in both directions between the $A D$ and the PoS; whereas the AD is necessary for the presence of HD cell activity in the PoS, the PoS appears important in allowing visual landmarks to exert control over the preferred firing direction of AD HD cells. These findings have implications for several computational models that propose to account for the generation of the HD cell signal.

Key words: head direction cells; anterior thalamus; presubiculum; postsubiculum; navigation; visual cues; landmarks; spatial orientation
Previous research has identified neurons in several brain structures that discharge as a function of the animal's head direction in the horizontal plane, independent of its location in the environment. These brain areas include the postsubiculum (PoS) (Ranck, 1984; Taube et al., 1990a), lateral dorsal thalamus (LD) (Mizumori and Williams, 1993), striatum (Wiener et al., 1993), retrosplenial cortex (Chen et al., 1994), and the anterior dorsal nucleus of the thalamus (AD) (Taube, 1995). Figure 1 summarizes the major connections between structures containing $\mathrm{HD}$ cells and other closely linked brain areas. Currently, it is not known to what extent the HD cells in any of these regions depend on input from the other structures. Is the HD signal conveyed from one structure to another or does it arise independently in each structure?

Because the AD and the deep layers of PoS are reciprocally connected with one another (Van Groen and Wyss, 1990c, 1995), this study examined the nature of interaction between these two structures by monitoring HD cell activity in one brain area after lesions to the other brain area. Previous studies have also shown that AD and PoS HD cells differ in their temporal relationship to the animal's head direction. Whereas AD HD cells tend to anticipate the animal's future directional heading by $\sim 25 \mathrm{msec}$, PoS HD cells encode the animal's present, or slightly past, directional heading (Blair and Sharp, 1995; Blair et al., 1997; Taube and Muller, 1997). In the first experiment, we examined the

Received May 23, 1997; revised July 28, 1997; accepted Sept. 15, 1997.

This work was supported by National Institute of Mental Health Grants MH48924 and MH01286 to J.S.T. We thank Heather Brandling-Bennett for her assistance in screening animals.

Correspondence should be addressed to Jeffrey S. Taube, Dartmouth College, Department of Psychology, 6207 Gerry Hall, Hanover, NH 03755.

Dr. Goodridge's present address: Center for the Neural Basis of Cognition, 115 Mellon Institute, 4400 Fifth Avenue, Pittsburgh, PA 15213.

Copyright (C) 1997 Society for Neuroscience $0270-6474 / 97 / 179315-16 \$ 05.00 / 0$ effects of bilateral lesions of the AD on HD cell discharge in the PoS. In the second experiment, we examined the effects of bilateral PoS lesions on HD cell discharge in the AD.

The anterior thalamic nuclei are composed of three distinct subnuclei: AD, anterior ventral (AV), and anterior medial (AM). Although the AV nucleus also projects to the PoS, lesions were aimed primarily at the AD nucleus because all HD neurons identified in the anterior thalamic nuclei have been localized to the AD (Taube, 1995).

The PoS, parasubiculum, presubiculum, and subiculum form the subicular complex. However, some investigators do not recognize a distinct PoS area and consider the PoS to be the dorsal portion of the presubiculum (Blackstad, 1956; Witter et al., 1989). Using this classification scheme the lesions we conducted would only be considered partial lesions of the presubiculum. However, because the ventral portions of the presubiculum do not project to AD (Van Groen and Wyss, 1990b), lesions of only the dorsal areas should be sufficient to remove any direct connections, and the transfer of any directional heading information, from the presubiculum to the AD.

Preliminary results concerning some of these findings have been published previously (Goodridge and Taube, 1993, 1994).

\section{MATERIALS AND METHODS}

\section{Subjects}

Twenty-four female, Long-Evans rats were placed on a food-restricted diet $(\sim 15 \mathrm{gm} / \mathrm{d})$ at $4-6$ months of age. Animals were housed in pairs until the time of surgery, after which they were housed individually. From birth on, animals were maintained on a $14 \mathrm{hr}$ light $/ 10 \mathrm{hr}$ dark cycle.

\section{Apparatus and training procedures}

Before surgery and after being placed on a food-restricted diet, all rats were given 1-2 weeks of training retrieving food pellets thrown randomly into a gray cylindrical apparatus ( $76 \mathrm{~cm}$ diameter, $51 \mathrm{~cm}$ high). Taped to one side of the cylinder was a white cue card that occupied $\sim 100^{\circ}$ of arc 


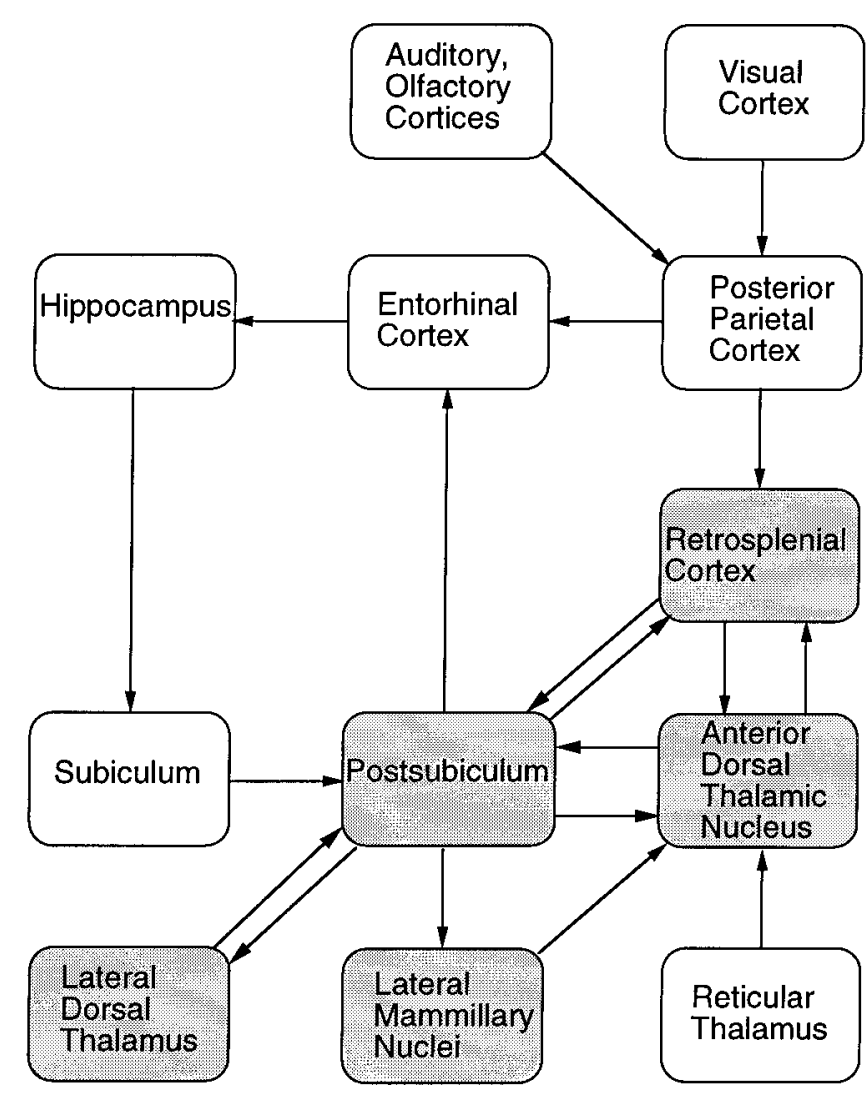

Figure 1. Diagram illustrating the major connections between brain areas thought to be involved in the processing of the HD cell signal. Shaded regions are areas where HD cells have been identified.

and served as the sole orienting stimulus placed into the environment by the experimenter. Surrounding the gray cylinder was a floor-to-ceiling black curtain draped from a circular copper rod ( $2 \mathrm{~m}$ diameter) that was suspended from the ceiling. The floor of the cylinder was composed of a sheet of gray photographic backdrop paper and was replaced when it became soiled from rat boli or urine marks. During the training period, a pair of animals was simultaneously given $15 \mathrm{~min} / \mathrm{d}$ in which to roam the cylinder and retrieve $20 \mathrm{mg}$ food pellets scattered on the floor (P. J. Noyes). One or two pellets were thrown pseudorandomly into the cylinder every $10-15 \mathrm{sec}$ by an experimenter standing outside the curtainedoff area. The purpose of this task was to encourage the rat to visit all parts of the cylinder and thereby sample different head orientations at different locations. Training was considered complete when the rats spent $80-90 \%$ of their time searching for food.

\section{Surgical procedures}

For 19 of 24 rats, lesions of either the PoS or the AD were made with ibotenic acid. The ibotenic acid (Bioresearch Technologies) was dissolved in sodium PBS $(10 \mathrm{mg} / \mathrm{ml}$, vehicle $\mathrm{pH}$ 7.2), and then $5 \mu \mathrm{l}$ aliquots were frozen until the day of surgery. The ibotenic acid was pressureinjected into the brain through a glass micropipette with a tip diameter of $\sim 50 \mu \mathrm{m}$. After injection, the pipette remained in the brain for at least 30 $\mathrm{sec}$ and was then gradually withdrawn. A 10-wire microelectrode array (for details on electrode construction, see Kubie, 1984) was implanted into either the PoS or the AD after all the drug injections had been completed.

Experiment 1: AD lesions/PoS recording. Bilateral lesions were aimed at the AD nucleus of the thalamus in 13 rats. Five of the 13 animals received electrolytic lesions (1-2 mA of anodal current for 10-15 sec). A metal insect pin (000) with a 1-mm-long uninsulated, pointed tip was placed into one site per hemisphere $(1.5 \mathrm{~mm}$ posterior to bregma, $1.4 \mathrm{~mm}$ lateral to bregma, and $4.5 \mathrm{~mm}$ ventral to the cortical surface). The remaining eight rats received neurotoxic lesions of the anterior thalamus. Three of the eight rats were lesioned with $0.1-0.15 \mu \mathrm{l}$ of ibotenic acid injected into one site per hemisphere $(1.4 \mathrm{~mm}$ posterior to bregma, 1.4 $\mathrm{mm}$ lateral to bregma, and $4.8 \mathrm{~mm}$ ventral to the cortical surface). The other five rats received $0.1-0.15 \mu l$ injections in two sites per hemisphere (1.4 $\mathrm{mm}$ posterior to bregma, $1.4 \mathrm{~mm}$ lateral to bregma, $4.8 \mathrm{~mm}$ ventral to the cortical surface; $1.3 \mathrm{~mm}$ posterior to bregma, $1.8 \mathrm{~mm}$ lateral to bregma, $4.35 \mathrm{~mm}$ ventral to the cortical surface). In each rat, after the lesions were performed the recording electrode array was implanted just dorsal to the PoS ( $6.7 \mathrm{~mm}$ posterior to bregma, $2.8 \mathrm{~mm}$ lateral to bregma, and 1.6 ventral to the cortical surface).

Experiment 2: PoS lesions/AD recording. Neurotoxic lesions of the PoS were conducted in 11 rats. Ibotenic acid $(0.05-0.15 \mu \mathrm{l}$ per site) was injected bilaterally at $2(n=3), 3(n=2), 4(n=3)$, or $5(n=3)$ sites/hemisphere. The injection coordinates are shown in Table 1 . The primary purpose of the four- and five-site lesions was to increase the amount of damage to the posterior parts of the PoS. In each rat, after the injections were made the electrode array was implanted just dorsal to the $\mathrm{AD}$ thalamus $(1.5 \mathrm{~mm}$ posterior to bregma, $1.3 \mathrm{~mm}$ lateral to bregma, and $3.7 \mathrm{~mm}$ ventral to the cortical surface).

\section{Screening procedures}

After 5-7 d of recovery from surgery, each of the electrodes was monitored for cellular activity. All "screening" for cells took place in the same cylinder where the animal had initially been trained to retrieve food pellets. The signal from each of the 10 electrodes was monitored individually while the rat's behavior was observed on a video monitor with a video camera suspended $\sim 3 \mathrm{~m}$ above the cylinder. When the activity on all the wires had been assessed and if none of the 10 wires contained an $\mathrm{HD}$ cell or other activity of interest, the electrode array was advanced $30-120 \mu \mathrm{m}$ ventrally into the brain. After waiting at least $4 \mathrm{hr}$, but usually $24 \mathrm{hr}$, the 10 wires were monitored again for activity.

\section{Recording procedures}

Once an HD cell or other cell type of interest was identified during a cell screening session, the room was prepared for a recording session in which the activity of the cell and the animal's ongoing location and head direction could be measured. In the current study, an HD cell was only considered to be a distinct cell from an HD cell previously recorded in that animal if the electrode array had been turned $>200 \mu \mathrm{m}$ since the last HD cell was identified on that wire. The activity of a cell was isolated from background noise using a series of window discriminators (Bak Electronics), and the animal's ongoing head direction was measured using a two-spot video tracking system (for details, see Taube et al., 1990a). A red light-emitting diode (LED) was positioned over the animal's snout, and a green LED was positioned $10-15 \mathrm{~cm}$ away over the rat's back. The location of each LED and the firing rate of the cell were sampled at $60 \mathrm{~Hz}$ and stored on a computer. For each recording session, the firing rate of the cell in relation to the rat's head direction was computed and analyzed off-line.

Various manipulations with external cues were used to assess the response properties of the recorded cells. These procedures included a Cue Rotation series, Cue Removal series, and Novel Environment series. Throughout all sessions, we tried to restrict the available external orientation cues to the ones intentionally manipulated by the experimenter (such as the white card). The door to the recording room was kept closed, and all lights were turned off except for the four symmetrically spaced lights directly above the cylinder. During each session, the experimenter threw food pellets into the chamber over the top of the black curtain from different parts of the room so that footsteps could not be used as auditory cues. In addition, white noise emanating from a speaker on the ceiling was used to mask any auditory cues that were present in the external environment. The rat was brought into the curtained-off area in an enclosed cardboard box through one of three pseudorandomly selected partitions in the curtains. The experimenter then placed the rat into a pseudorandomly chosen quadrant of the cylinder and left the curtained area through different partitions each time. Unless specified otherwise, before each session the floor paper was replaced with a clean sheet to prevent the animals from using markings on the floor as orientation cues. In addition, each animal was gently spun in a box for 1-2 min before each session to prevent it from using idiothetic cues (i.e., vestibular, proprioceptive, and motor). The spinning was accomplished by rotating the box randomly in different directions while the experimenter walked around the cylinder. These procedures were similar to the methods used in previous research in nonlesioned animals (Taube et al., 1990b; Taube, 1995; Goodridge and Taube, 1995; Taube and Burton, 1995).

The Cue Rotation series commenced with a session in which cell 
Table 1. Ibotenic acid injection coordinates for PoS lesions

\begin{tabular}{|c|c|c|c|c|}
\hline & Two site lesions & Three site lesions & Four site lesions & Five site lesions \\
\hline Injection 1 & $6.7 \mathrm{P}, 2.5 \mathrm{~L}, 2.6 \mathrm{~V}$ & $6.7 \mathrm{P}, 2.5 \mathrm{~L}, 2.6 \mathrm{~V}$ & $6.7 \mathrm{P}, 2.5 \mathrm{~L}, 2.6 \mathrm{~V}$ & $6.7 \mathrm{P}, 2.7 \mathrm{~L}, 2.6 \mathrm{~V}$ \\
\hline Injection 2 & $7.3 \mathrm{P}, 3.5 \mathrm{~L}, 3.5 \mathrm{~V}$ & $7.0 \mathrm{P}, 3.2 \mathrm{~L}, 3.4 \mathrm{~V}$ & $7.3 \mathrm{P}, 3.5 \mathrm{~L}, 3.5 \mathrm{~V}$ & $7.3 \mathrm{P}, 2.8 \mathrm{~L}, 3.6 \mathrm{~V}$ \\
\hline Injection 3 & & $7.4 \mathrm{P}, 3.7 \mathrm{~L}, 3.8 \mathrm{~V}$ & $7.6 \mathrm{P}, 3.4 \mathrm{~L}, 3.0 \mathrm{~V}$ & $7.3 \mathrm{P}, 3.5 \mathrm{~L}, 2.4 \mathrm{~V}$ \\
\hline Injection 4 & & & $8.0 \mathrm{P}, 3.3 \mathrm{~L}, 2.4 \mathrm{~V}$ & $7.6 \mathrm{P}, 3.4 \mathrm{~L}, 3.0 \mathrm{~V}$ \\
\hline Injection 5 & & & & $8.0 \mathrm{P}, 3.3 \mathrm{~L}, 2.4 \mathrm{~V}$ \\
\hline
\end{tabular}

All values are shown in millimeters with respect to bregma. All injections were bilateral.

P, Posterior; L, lateral; V, ventral from cortical surface.

activity was monitored for $8 \mathrm{~min}$ with the cue card and cylinder in the spatial configuration that was used throughout all the screening sessions (Standard 1). The animal was then removed from the cylinder, detached from the recording cable, and placed into a cardboard box. The floor paper underneath the cylinder was replaced with a new sheet, and the cue card was rotated either $90^{\circ}$ clockwise or $90^{\circ}$ counterclockwise. The animal was then gently spun in the box for 1-2 min, reattached to the cable, and returned to the cylinder. The experimenter exited the curtained-off area and recorded the activity of the cell for another 8 or 16 min session (Rotation session). At the completion of the Rotation session, the animal was again placed into the cardboard box, the floor paper replaced, and the cue card returned to its standard position. After being spun in the box, the rat was reattached to the cable, and the cell was monitored for a final 8 or 16 min session (Standard 2).

Similar to the Cue Rotation series, the Cue Removal series began with an 8 min session in which the cue card and cylinder were in their standard position (Standard). When the session was finished, the animal was removed from the chamber, detached from the cable, and placed into a cardboard box. Then the cue card was removed from the cylinder, and the floor paper was replaced with a new sheet. The animal was then spun for $1-2 \mathrm{~min}$ in the cardboard box, reattached to the cable, and placed into the cylinder for another 8 min session (Cue Removal). At the completion of this session, the animal was detached from the cable and returned to its home cage.

The Novel Environment series was intended to assess the extent to which HD cells in PoS-lesioned animals can use idiothetic cues for updating their preferred firing direction. HD cells monitored in intact animals usually maintain their preferred firing direction when the animal enters a novel environment (Taube and Burton, 1995). Because there are no familiar cues in the novel environment that the cells can use to establish their preferred firing direction, the cells may be maintaining their orientation by accessing idiothetic information. The Novel Environment series used a dual-chamber apparatus that consisted of a cylinder (similarly proportioned to the screening cylinder) attached to a gray rectangular apparatus by means of a U-shaped passageway (Fig. 2). Both the passageway and rectangle were novel environments to the animal. In the first session, the HD cell was monitored for $8 \mathrm{~min}$ while the animal retrieved food pellets in the cylinder (Standard). Then, a door separating the cylinder from the passageway was opened to allow the animal to leave the cylinder. If the animal did not leave the cylinder within the first $4 \mathrm{~min}$ of the session, the experimenter gently coaxed it into the passageway. The door connecting the cylinder and passageway was then replaced so that the rat could no longer return to the cylinder but could freely move between the passageway and rectangle. Cell activity was then monitored for 8-10 min (Novel session), after which the animal was removed from the apparatus, detached from the recording cable, and returned to its home cage. Because this manipulation required the rectangle and passageway to be novel to the animal, it was conducted no more than once per animal.

\section{Data analysis}

The relationship between the activity of a recorded neuron and the rat's head direction during each session was determined by constructing a firing rate by head direction plot. For each $1 / 60 \mathrm{sec}$ sample, the computer stored the $x, y$ coordinates of the red and green LEDs and the number of spikes discharged by the cell. The $x, y$ coordinates of the LEDs were then used to compute the rat's head direction and to assign each sample to one of 60 possible bins, with each bin representing a $6^{\circ}$ portion of head direction space. A firing rate by head direction tuning curve was constructed by plotting the mean firing rate (ordinate) of the cell in each bin as a function of the animal's directional heading (abscissa).

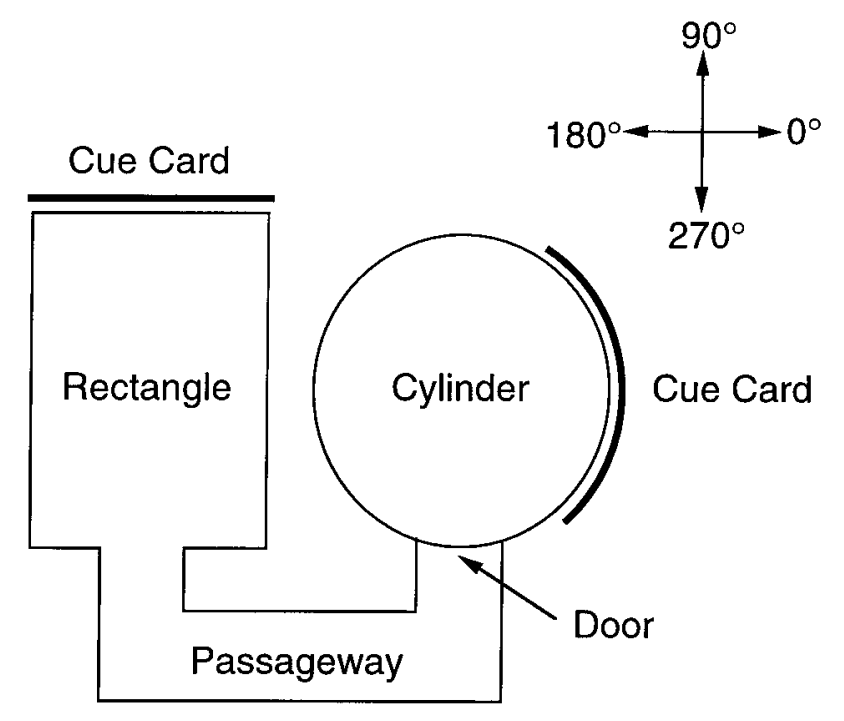

Figure 2. Overhead view of the dual-chamber apparatus. The bold lines indicate the positions of white cue cards placed on the inside walls of the enclosure. The cue cards extended from the floor to the top of the apparatus.

To determine the mean directional shift between different recording sessions, analyses used the total number of manipulations conducted rather than the number of cells recorded or the number of rats. Thus, if two cells were recorded simultaneously, and their waveforms were equally well isolated, the change in the preferred firing direction between two sessions was computed as the average of the two cells. However, if the waveforms of one of the two cells were considerably better isolated than those of the other cell, its responses were chosen to represent the activity of both cells. Furthermore, each environmental manipulation was treated equally, regardless of whether it was the first or last time the manipulation was performed on that particular rat. These procedures were justified on the basis of previous results (and confirmed in the present study), indicating that the variability in the response of the preferred firing direction of an HD cell can be attributed to the details of the particular manipulation and not to the intrinsic properties of the cell. Previous studies have shown that the preferred directions of HD cells recorded simultaneously shift in register (Taube et al., 1990b; Goodridge and Taube, 1995). Thus, the response of one HD cell in the population is sufficient to accurately predict the response of other HD cells recorded in the same region. If we had treated the results from simultaneously recorded cells separately, we would have biased our calculations in favor of those manipulations that occurred when multiple cells were recorded. Before we performed any analyses that used the number of manipulations rather than the number of cells, we first assessed whether simultaneously recorded HD cells in lesioned animals continued to shift in register. Once the angular shift was calculated for each manipulation, a Rayleigh test was used to measure whether a distribution of angular shifts was significantly different from the uniform distribution (Batschelet, 1981).

\section{Tuning curve parameters}

We calculated the peak firing rate, preferred firing direction, background firing rate, directional firing range, and asymmetry of the tuning curve of 
each cell using a triangular model (for details, see Taube et al., 1990a). To determine the angular shift in the preferred firing direction from one session to another, the firing rate by head direction tuning curve from one session was shifted in $6^{\circ}$ increments until it was maximally correlated with the tuning curve from the other session. The number of degrees the tuning curve had to be shifted to produce a maximum correlation was considered to be the amount that the preferred firing direction of the cell had shifted from one session to another.

\section{Time shift analysis}

To determine whether the temporal relation between HD cell firing and the rat's directional heading was affected by the lesions, we conducted two different types of analyses. The first method examined the difference between the preferred firing direction of the cell when the animal was turning its head in the counterclockwise or clockwise directions (Blair and Sharp, 1995). If the activity of the cell led or lagged the animal's head direction, then the cell would reach its maximum firing rate at a different head direction for counterclockwise and clockwise head turns. The difference in the cell's preferred firing direction for clockwise and counterclockwise turns is referred to as $\delta$. The greater the degree to which the cell anticipated the animal's current head direction, the larger the $\delta$. Thus, if HD cells in lesioned animals led or lagged the animal's head direction by different amounts than HD cells in control animals, then one would expect the two populations of cells to differ in the size of $\delta$. We calculated $\delta$ by constructing two separate tuning curves, one for clockwise head turns $>90^{\circ} / \mathrm{sec}$ and one for counterclockwise head turns $>90^{\circ} / \mathrm{sec}$. Samples in which the animal's angular velocity was $<90^{\circ} / \mathrm{sec}$ were not included in the analyses. The angular shift between the preferred firing direction of the counterclockwise and clockwise head turns was computed using the same method as that used for computing the angular shift of an HD cell from one recording session to the next (see above).

The second method for determining the extent to which HD cell firing led or lagged the rat's head direction involved shifting the spike series in relation to the head direction series and then comparing the tuning curves at various levels of alignment. The amount and direction the spike series had to be shifted to produce the strongest association between head direction and firing rate indicated whether the discharge of the cell most accurately predicted the animal's past, current, or future head direction. The strength of the association between firing rate and head direction at different points in time was measured with three parameters: peak firing rate, range width, and information content. Range width is similar to directional firing range but measures the width of the tuning curve of the cell at $30 \%$ of the peak firing rate of the cell, rather than at its background levels. Information content represents how much information each spike conveys about the rat's directional heading and was adapted to HD cells according to the model used by Skaggs et al. (1993) for place cells. The amount that the discharge of the cell led or lagged head direction was defined as the number of samples that the spike series needed to be shifted to attain the maximum peak firing rate, minimum range width, or maximum information content.

Once the optimal time shift values were calculated for each cell, we determined whether there was an overall difference in these values between lesioned and intact animals. We used two different methods for this calculation. In the first method, we computed the mean of the optimal time shift values for cells in lesioned and intact animals and determined whether these means were statistically different. In the second method, for each cell we plotted peak firing rate, range width, and information content as a function of time shift. Then, each graph was normalized by dividing the value of the parameters in each time shift category by the optimum value for that parameter (maximum peak firing rate and information content, minimum range width). As a result of this procedure, the optimum value of each parameter received a value of 1.00 . A composite graph for intact animals and lesioned animals was then produced by averaging the normalized parameter values in each time shift category across all cells. Each composite graph was then normalized in the same way that the individual cell graphs were normalized, and we compared the shape and position of the composite graphs in lesioned and intact animals. To facilitate comparison of the range width plot with the other measures, we calculated the reciprocal of range width before normalizing the function. For further details concerning the time shift analyses, see Taube and Muller (1997).

\section{Angular head velocity analysis}

The firing rate of AD HD cells in intact animals is modulated a little $(r=$ 0.0154 ) by the animal's angular head velocity (Taube, 1995). We examined whether this sensitivity was also present in AD HD cells from PoS-lesioned animals using the same procedures as described by Taube (1995). First, we selected from an 8 min recording session all those samples in which the animal was pointing its head within a $24^{\circ}$ arc centered on the preferred direction of the cell. We then computed the head direction in each of those samples, and in the two samples before and after the chosen sample. The angular head velocity of the center sample was defined as the slope of the best fit line between these five head direction points. The absolute value of angular velocity was used for each selected sample to take into account only the speed of the animal's head movements and not the direction of head turn. Finally, the number of spikes fired and the rat's angular head velocity were correlated across all selected samples.

\section{Control groups}

The control groups used for each experiment consisted of HD cells recorded from intact animals in previous studies from our laboratory (PoS, $n=55$; AD, $n=33$ ) (e.g., Taube et al., 1990a,b; Goodridge and Taube, 1995; Taube, 1995; Taube and Burton, 1995). Control values for tuning curve parameters, angular head velocity, and time shift analyses were derived from standard sessions. The control data for the Cue Card Rotation, Cue Card Removal, and Novel Environment series were drawn from the same studies, which used similar procedures to conduct these environmental manipulations. In particular, attempts were made to limit the cues that HD cells could use to establish their orientation to those explicitly manipulated by the experimenter. These procedures included disorientation treatment in between consecutive recording sessions, random placement of the animal into the apparatus at the beginning of every session, and use of a black curtain around the apparatus to block room cues.

\section{Histology}

When the electrodes had been advanced at least $1.8 \mathrm{~mm}$ into the brain (four complete turns of the electrode screws), or the activity profile on the 10 electrodes suggested that the electrode array had passed through the PoS or AD, rats were anesthetized (Nembutal, $1.5 \mathrm{ml} / \mathrm{kg}$, i.p.), and a small anodal current $(10-20 \mu \mathrm{A}$ for $10 \mathrm{sec})$ was passed through one of the electrodes that had most recently recorded an HD cell to later conduct a Prussian blue reaction. The rats were then perfused with saline for 5 min followed by $10 \%$ formalin (in saline) for $10 \mathrm{~min}$. The brain was removed and immersed in $10 \%$ formalin for at least $48 \mathrm{hr}$. The brain was then placed in a $10 \%$ formalin solution that contained $2 \%$ potassium ferrocyanide (which stained the site of the current lesion described above) for $24 \mathrm{hr}$ and then reimmersed in $10 \%$ formalin for $24 \mathrm{hr}$ before being placed in $20 \%$ sucrose for at least $48 \mathrm{hr}$. The brains were blocked, frozen with dry ice, and then sectioned $(30 \mu \mathrm{m})$ in the coronal plane on a cryostat and mounted onto microscope slides. After they dried for at least $12 \mathrm{hr}$, the slides were stained with cresyl violet and examined microscopically for localization of the recording sites and the extent of the lesions.

It was not necessary to determine the proportion of $\mathrm{AD}$ lesioned because all but one of the AD lesions were complete. However, because many of the PoS-lesioned animals did not have complete lesions, we developed a measure of lesion size for these animals. Lesion size was estimated by comparing the extent of the lesion with the area classified as PoS (as defined by Van Groen and Wyss, 1990c). For this analysis, however, the most posterior portion of the PoS was not defined as PoS because some investigators have considered this region to be part of the retrosplenial cortex (area 29e) (Haug, 1976). Consistent with this notion, it has also been found that the connectivity of this posterior region is different from the PoS (J. S. Taube and D. G. Amaral, unpublished observations). Consequently, only the anterior dorsal portions labeled as presubiculum by Paxinos and Watson (1986) [anterior-posterior (AP): -5.8 to -7.8 ] were considered PoS. To establish the percentage of the PoS-lesioned in each animal, schematic diagrams of the rat brain were selected from the Paxinos and Watson (1986) atlas at the following AP extents (mm posterior to bregma): 5.3, 5.8, 6.3, 6.8, 7.3, 7.8, 8.3. Each schematic was assigned a total-point value that was directly proportional to the size of the PoS depicted in that schematic. After the brains were sectioned and the tissue was stained with cresyl violet, each animal's brain was examined microscopically, and the parts of the schematics that 
A

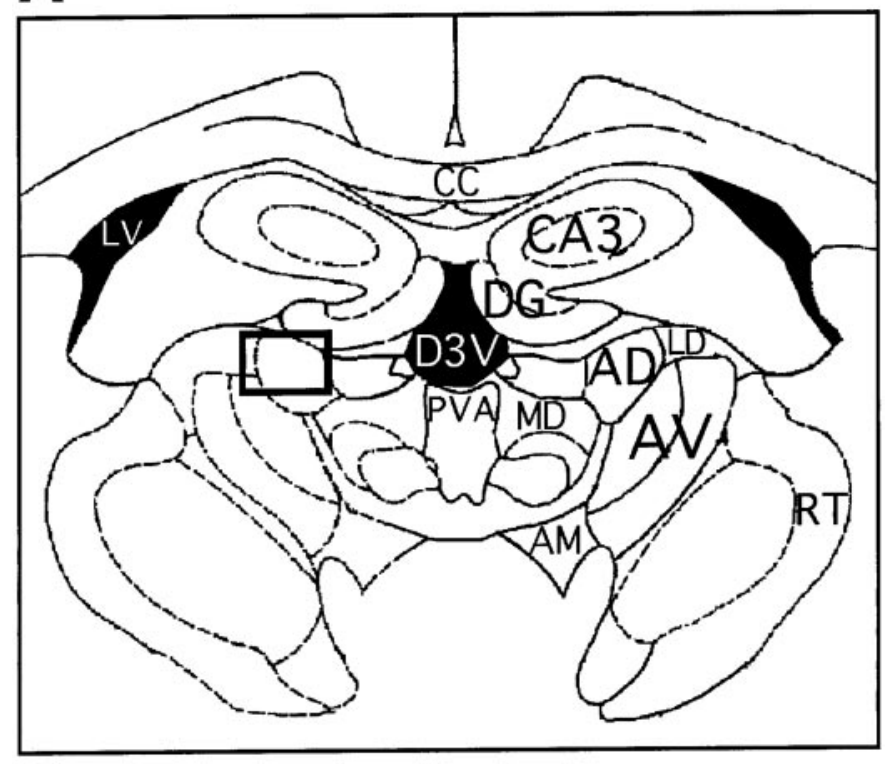

B

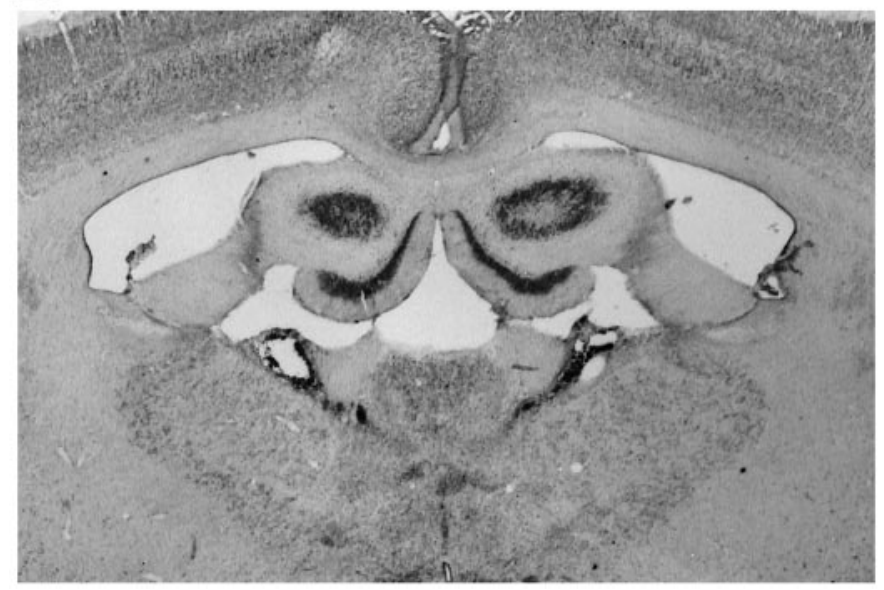

Figure 3. A, Schematic diagram showing the structures involved in the lesions for Experiment 1, including the various anterior thalamic nuclei. $A D$, Anterior dorsal thalamic nucleus; $A M$, anterior medial nucleus; $A V$, anterior ventral thalamic nucleus; $c c$, corpus callosum; $D G$, dentate gyrus; $L D$, lateral dorsal thalamic nucleus; $L V$, lateral ventricle; $M D$, medial dorsal thalamic nucleus; $P V A$, paraventricular thalamic nucleus; $R T$, reticular thalamic nucleus; $s m$, stria medullaris. $B$, Photograph from a cresyl violet-stained coronal section in an animal that received bilateral electrolytic lesions to the anterior thalamus. Damage was confined primarily to $\mathrm{AD}$, with less damage to $\mathrm{AV}$ and $\mathrm{AM}$. In addition, unlike the neurotoxic lesions, the medial parts of the thalamus remained intact.

corresponded to the location of the lesion were shaded. These shaded schematics were then assigned a score based on the percentage of the PoS damaged and the total number of points available for that schematic. When all the schematics for an animal had been examined, we computed the overall percentage of the PoS that was damaged.

\section{RESULTS}

\section{Experiment 1: AD lesions}

In all 13 animals that received AD lesions, the electrode arrays were judged to have advanced completely through the PoS. A representative photograph of a section in which an electrode array passed through the PoS is depicted in Figure $4 E$. Twelve animals were judged to have complete lesions of the AD, and one animal had only a partial lesion of the AD. Figure $3 A$ shows a schematic diagram of the anterior thalamic region, and Figure $3 B$ shows a representative photograph from an animal with a complete electrolytic lesion. Figure 4 shows representative photographs of a coronal section from an animal with a complete neurotoxic lesion $(A, C)$ and from a nonlesioned animal $(B, D)$. Many of the complete ibotenic acid lesions also included damage to the anterior dorsal portion of the LD thalamus, part of the dentate gyrus and hippocampal CA3, and some medial thalamic structures such as the medial dorsal thalamus. In addition, in most cases there was only minor damage to the cortex overlying the AD nucleus. In contrast, the electrolytic lesions exhibited a reverse pattern. Although they mostly spared the hippocampus, LD, and medial thalamic structures, they substantially damaged the overlying cortex. The difference in these results can be accounted for by the small diameter of the micropipette used to inject the ibotenic acid relative to the large insect pin used for the electrolytic lesions. In addition, the unpredictability of the spread of the ibotenic acid and the sensitivity of the hippocampal neurons to excitotoxins may explain this increased damage to the LD and hippocampal regions. However, the primary shared region of damage across both types of lesions was the AD.

A total of 348 cells were isolated in the 12 completely lesioned animals. None of these cells was classified as an HD cell. Thus, despite a careful search for any type of cell activity that was correlated with the animal's directional heading, none could be detected. Forty cells were classified as theta cells. In the remaining cells, we could not identify any spatial or behavioral correlate. Five of these undefined cells were recorded on the computer, and none of their discharge characteristics had any apparent relation to head direction.

Four HD cells were identified in the one partially lesioned animal. Only one of these cells was sufficiently isolated from background noise to allow for an accurate assessment of its tuning curve. A firing rate by head direction plot of this cell (Fig. 5B) revealed that its directional firing range was substantially greater than any PoS HD cell previously recorded from an intact animal (e.g., Fig. 5A). Although directional firing ranges of previously recorded PoS HD cells ranged from 60.9 to $136.1^{\circ}$ (Taube et al., 1990a; Goodridge and Taube, 1995; Taube and Burton, 1995), this cell had a directional firing range of $240^{\circ}$. To examine whether this wider range was caused by drift in the preferred firing direction across the $8 \mathrm{~min}$ session, firing rate by head direction plots were constructed on the basis of the first and last 3 min of the session. Figure $5 C$ shows that the directional firing range of the cell was equally large for both 3 min epochs and was comparable to its range across the entire 8 min session. Thus, the wider directional firing range of this cell cannot be attributed to drift in its preferred firing direction.

The activity of this cell was also assessed for its response to a Cue Rotation series. The preferred firing direction of the cell shifted by a similar amount and in the same direction as the cue card. Figure $5 D$ shows a plot of each of these three sessions. Thus, although the tuning curve of the cell is different from those found in intact animals, its responsiveness to the cue card was similar to HD cells found in intact animals (Taube et al., 1990b).

\section{Experiment 2: PoS lesions}

A total of 119 cells were identified in the AD of the 11 PoSlesioned animals. This number is smaller than the total number of cells identified in the PoS in Experiment 1 because we recorded 


\section{A}

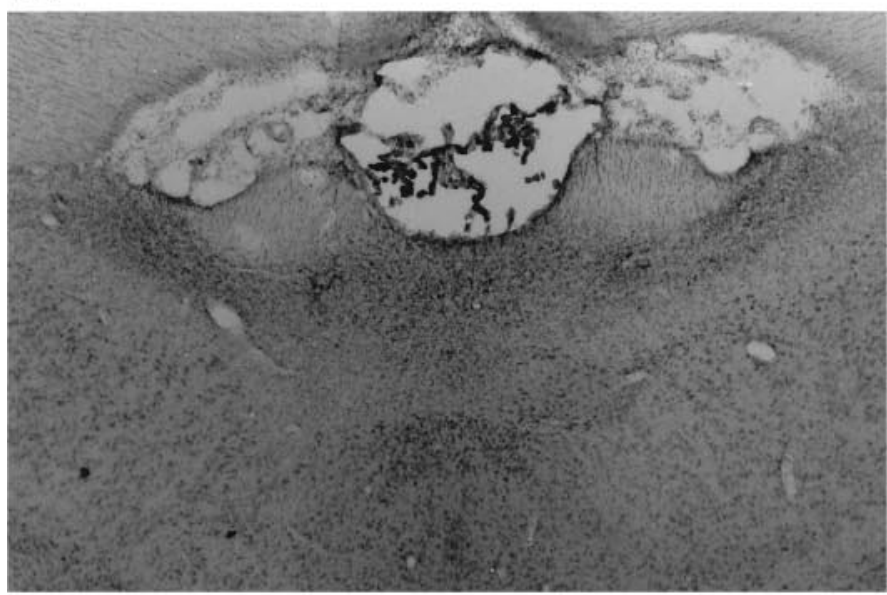

C

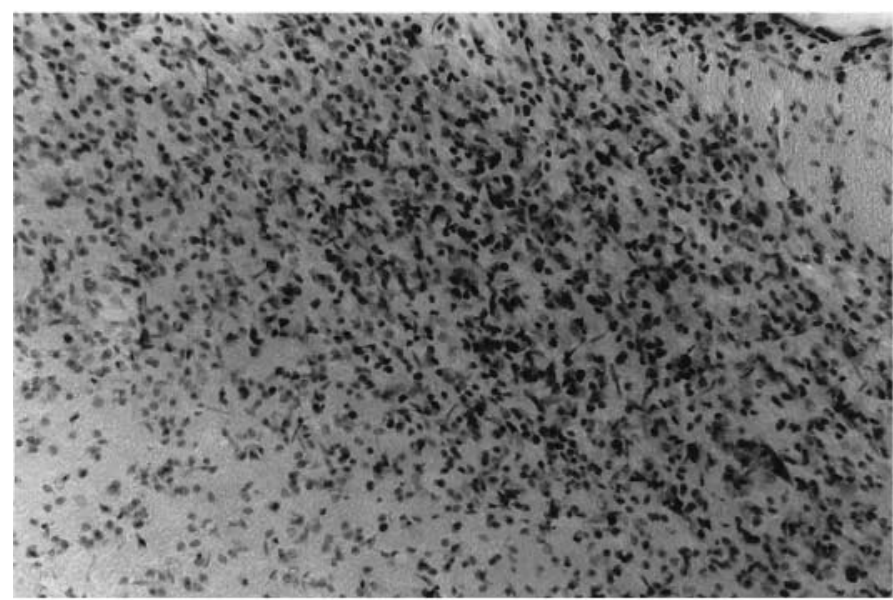

E

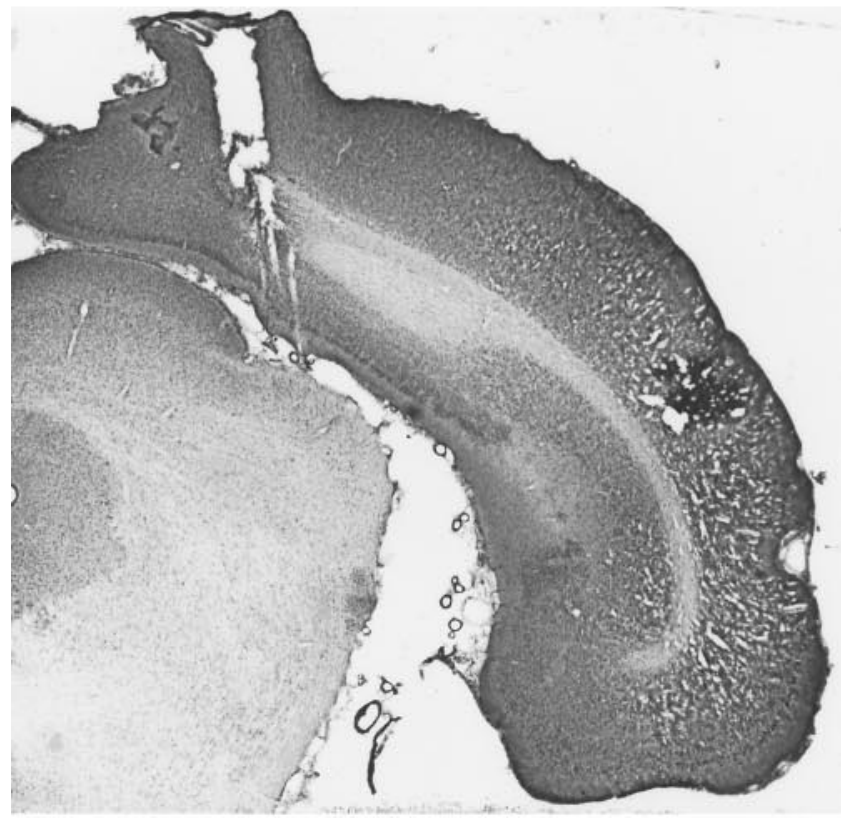

B

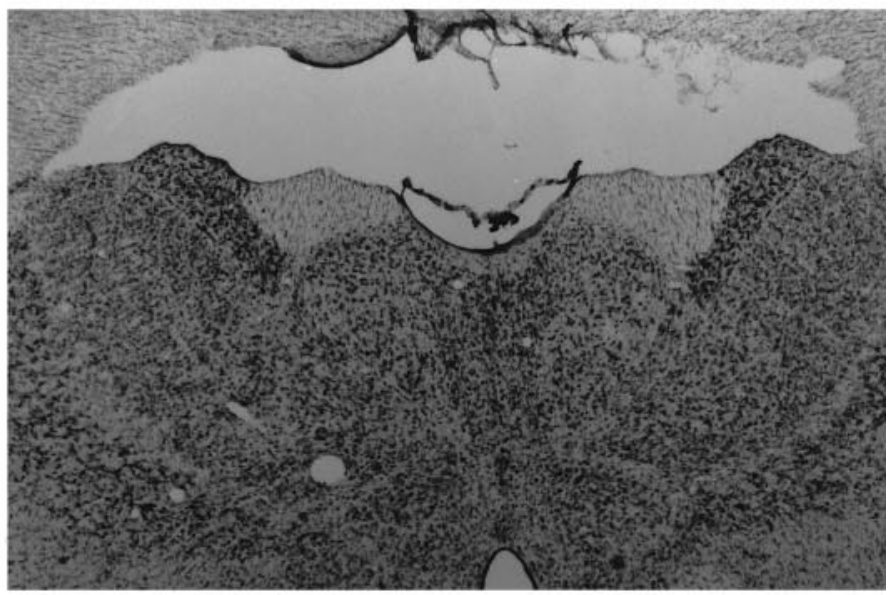

\section{D}

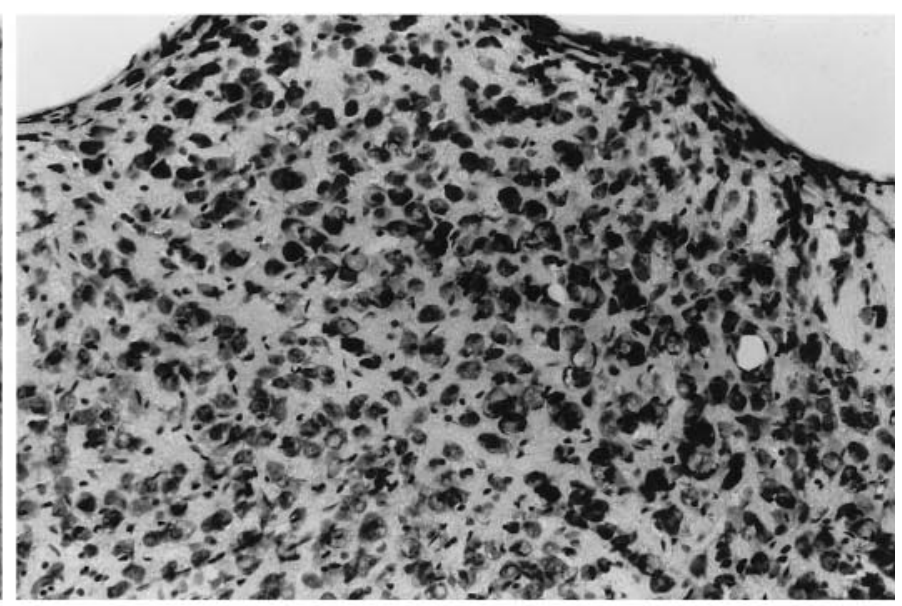

Figure 4. $A-E$, Photographs of cresyl violet-stained coronal sections through the anterior thalamus of an ibotenic acid-lesioned animal $(A, C)$ and an intact control animal $(B, D)$. The photographs in $A$ and $B$ are low-power views and represent the region enclosed in the large outer box as shown in Figure $3 A$. The divisions between the different nuclei in the anterior thalamus are clearly visible in $B$. The photographs in $C$ and $D$ are high-power views from the left anterior thalamic nucleus and represent the region shown by the small box in Figure $3 A$. Note the gliosis and absence of neurons in the lesioned rat $(C)$ compared with the intact animal $(D) . E$, Cresyl violet-stained coronal section through the PoS of the ibotenic acid-lesioned animal shown in $A$ and $C$. Individual wire tracts that have passed through the right PoS are clearly visible. 

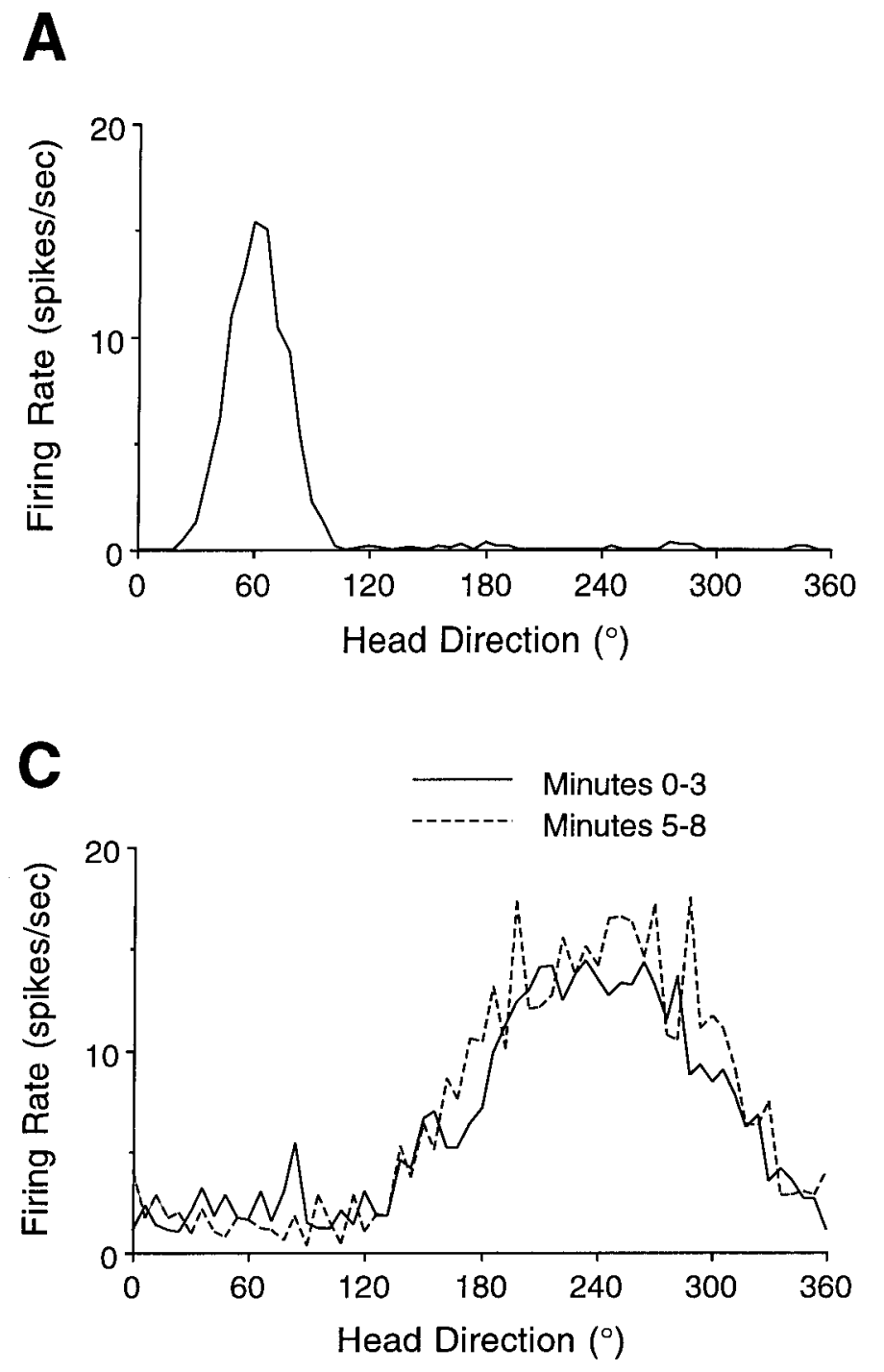

B
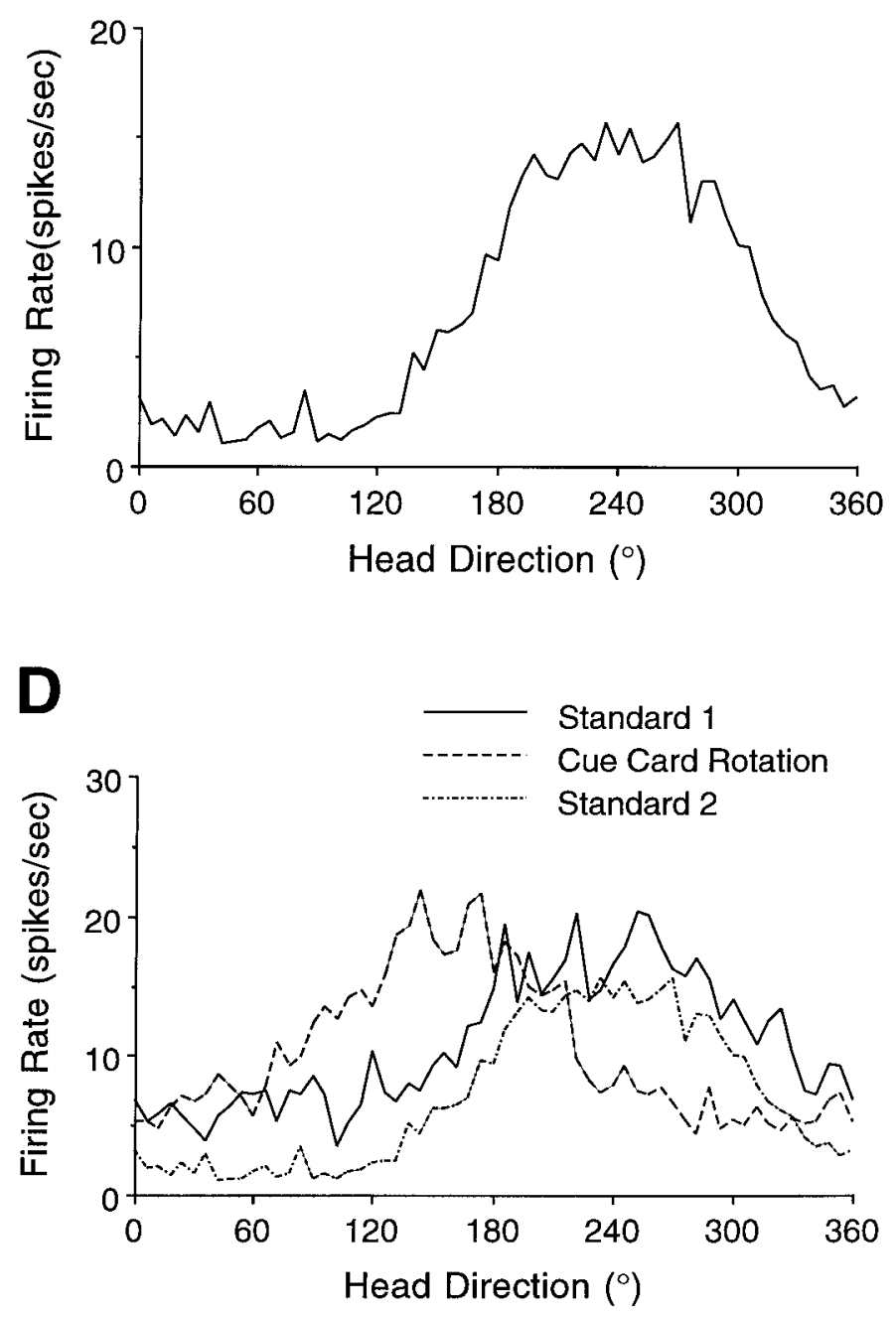

Figure 5. $A, B$, Firing rate versus HD plots of PoS HD cells in an intact animal $(A)$ and an animal with a partial lesion of the AD $(B)$. No HD cells could be identified in completely lesioned animals. Note the wide directional firing range in the cell from the partially lesioned animal. $C$, Firing rate versus HD plot of the cell depicted in $B$ for the first and last $3 \mathrm{~min}$ of an $8 \mathrm{~min}$ recording session. The tuning curves shown in the two 3 min epochs have similar preferred firing directions and directional firing ranges, a result that suggests that the large directional firing range is an intrinsic property of the firing of the cell. $D$, Response of the HD cell depicted in $B$ to a cue card rotation series. The preferred firing direction of the cell in the Standard 1 session was $\sim 240^{\circ}$. When the cue card was rotated $90^{\circ}$ clockwise, the preferred firing direction of the cell also shifted clockwise a similar amount $\left(\sim 84^{\circ}\right)$. Then, when the cue card was returned to its standard position, the preferred firing direction of the cell also returned to its original orientation.

over a larger brain area in Experiment 1 than in Experiment 2. Thirty-one cells $(26.1 \%)$ were classified as HD cells, with at least one HD cell recorded in each animal. The remaining cells had no observable behavioral or spatial correlate. Previous studies in nonlesioned animals reported that $56.1 \%$ of the cells recorded in the AD were classified as HD cells (Taube, 1995). Thus, the percentage of cells classified as HD cells in lesioned animals was considerably less than the percentage in nonlesioned animals. Unfortunately, it is difficult to determine whether the reduced percentage in lesioned animals is the result of the PoS damage or inter-experimenter differences in how cells are counted, because small variations in how cells are counted can affect these percentages.

The electrode tracts in nine animals passed through the AD, whereas the electrode tracts in one animal went through both the $\mathrm{AD}$ and $\mathrm{AV}$ nuclei. Poor histology in the remaining animal (caused by a brain infection) precluded the determination of the electrode tract. This animal was still included in the analyses below because the results from this animal were not different from the findings in the other PoS-lesioned animals, and the extent of its lesion was still discernible.

The mean size of the PoS lesions was 75\% (range, 50-95\%). Four of 11 animals had at least $85 \%$ of the PoS lesioned (two of these animals had at least $95 \%$ lesioned), three animals had between 80 and $85 \%$ of the PoS lesioned, and the remaining four animals had between 50 and $65 \%$ of the PoS lesioned. For the purpose of evaluating whether lesion size affected the cellular properties discussed below, the animals were divided into two groups. Group A consisted of six animals in which at least $80 \%$ of the entire PoS was lesioned and at least $80 \%$ of the right PoS was lesioned. Group B consisted of the five remaining animals. Because the anatomical evidence indicates that the PoS projects only 
to the ipsilateral AD and not to the contralateral AD (Van Groen and Wyss, 1990c), it was particularly important that the PoS in the right hemisphere was lesioned. In all but one animal, the right and left side lesions were similar in size. Figure $6 B, C$ shows representative photographs of coronal sections from the most completely $(B)$ and the least completely $(C)$ lesioned animals. For each dependent measure, analyses were first performed on the entire set of animals. Subsequently, we evaluated whether lesion size was correlated with each measure. In addition, a $t$ test was conducted that compared the six most lesioned animals (Group A) with the five least lesioned animals (Groups B).

Areas that were partially damaged in all of the animals in addition to the PoS included posterior portions of the dorsal subiculum, dentate gyrus, dorsal CA3 and CA1, and ventral retrosplenial cortex. The hippocampus and dentate gyrus sustained some damage in 8 of the 11 animals, and the ventral retrosplenial cortex and dorsal subiculum were lesioned slightly in all 11 animals. Thus, although none of these structures were lesioned as completely as the PoS, one or more of these areas was damaged in all animals.

\section{HD cell parameters}

Of the $31 \mathrm{HD}$ cells, the background firing rate, peak firing rate, directional firing range, and asymmetry of 25 cells that were adequately isolated were compared with a group of HD cells from intact animals. All four parameters were calculated from sessions with the cue card in its standard position. Table 2 shows the mean and SE of all parameters for HD cells in control and lesioned animals. There was no significant difference between the intact and lesioned animals for all the parameters except directional firing range, which was significantly greater in lesioned animals than in intact animals (pooled $t_{(55)}=4.7788$ ). Figure $7 \mathrm{~A}$ shows a plot of an AD HD cell from a control animal, and Figure $7 B, C$ show examples of HD cells from lesioned animals in Group A. The plots show that except for their directional firing ranges, the tuning curves of HD cells from PoS-lesioned and intact animals look qualitatively similar.

The larger directional firing range in PoS-lesioned animals could arise from drift in the preferred firing direction of the cell during the recording session. However, when the first and last 2 min of the 8 min sessions were compared for control and lesioned animals, there was no statistically significant difference between the two populations (pooled $t_{(54)}=0.036 ; p>0.05$ ).

The bottom row of Table 2 shows the correlation between lesion size and each of the four parameters. None of these correlations differed significantly from zero. However, there was a trend toward significance in the correlation between directional firing range and lesion size with a $p$ value $<0.07$. The positive correlation (0.365) indicates that as lesion size increased, directional firing range also increased. $t$ tests comparing Group A with Group B revealed a pattern similar to that of the correlationalanalysis. Although there were no significant differences between Groups A and B for peak firing rate, background firing rage, or asymmetry, the mean directional firing range of Group A cells was significantly higher than that of Group B cells (pooled $t_{(23)}=$ 2.429; $p<0.05)$. In addition, HD cells from Group B had a significantly larger mean directional firing range than HD cells in intact animals (pooled $t_{(41)}=2.06 ; p<0.05$ ). Taken together, these findings suggest that the failure to observe significant differences in three of the four parameters between control and lesioned animals cannot be attributed to the inclusion of too many animals with smaller lesions. In addition, they also indicate that

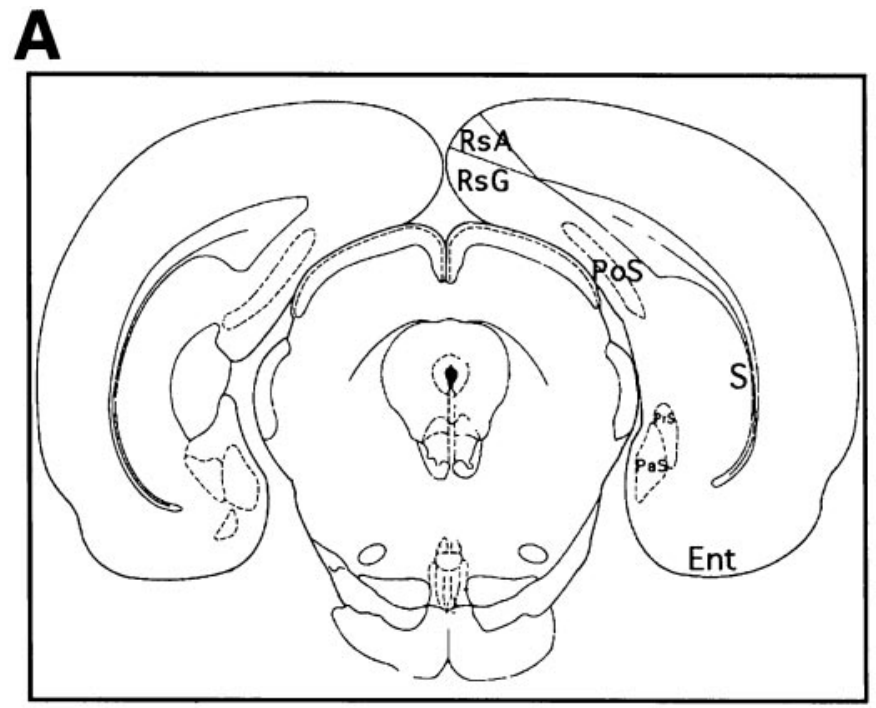

B

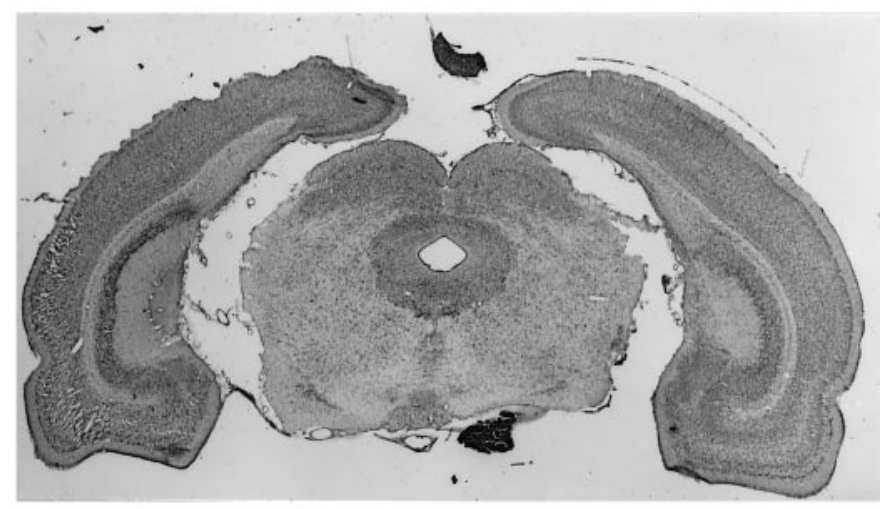

\section{C}

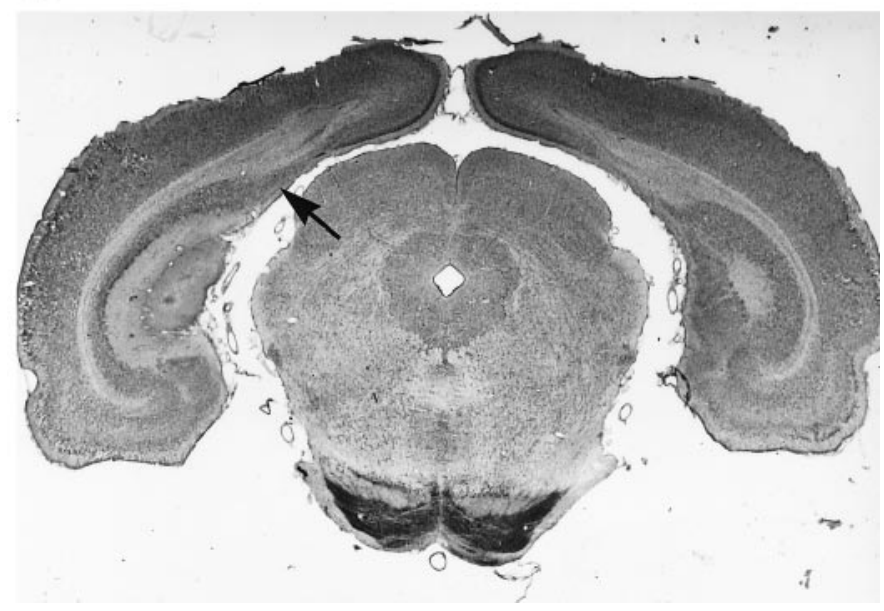

Figure 6. A, Schematic diagram of a rat brain showing a coronal section at the level of the PoS. Ent, Entorhinal cortex; PaS, parasubiculum; PoS, postsubiculum; $P r S$, presubiculum; $R s A$, agranular retrosplenial cortex; $R s G$, granular retrosplenial cortex; $S$, subiculum. $B, C$, Photographs showing cresyl violet-stained coronal sections through the PoS from a Group A rat considered to have a complete bilateral PoS lesion $(B)$ and a Group B rat considered to have a large but incomplete PoS lesion $(C)$. In the incompletely lesioned rat, some of the PoS medial and ventral to the corpus callosum remained intact (arrow). 
Table 2. Mean AD HD parameters after PoS lesions

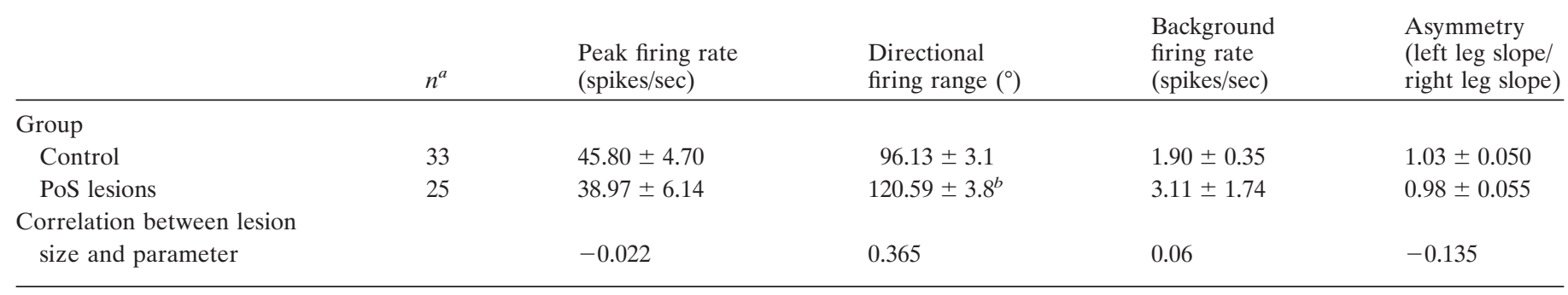

${ }^{a}$ All values of $n$ refer to the number of cells identified in the group, not the number of animals.

${ }^{b}$ Indicates significant $(p<0.05)$ pooled $t$ test relative to the control group.

although smaller lesions led to significantly higher directional firing ranges, larger lesions led to even larger range values.

\section{Angular head velocity}

The mean correlation between firing rate and angular head velocity cells in the PoS-lesioned animals was $0.103 \pm 0.015$ and was not significantly different from the value in control animals $(0.119 \pm 0.085)$. As with AD HD cells in control animals, however, this value was significantly greater than zero $\left(t_{(24)}=6.9 ; p<\right.$ $.05)$. This result suggests that PoS lesions do not alter the modest modulation of AD HD cell discharge by angular head velocity. The correlation between lesion size and the angular velocityfiring rate correlation was not significant. In addition, there was no significant difference between the mean angular velocityfiring rate correlation in HD cells from the group A rats and in HD cells from the group B rats. This result suggests that the failure to find a significant difference between control and PoSlesioned AD HD cells could not be attributed to the inclusion of partially lesioned animals.

\section{Time shift analysis}

HD cells in the AD have been found to anticipate the animal's head direction by $\sim 25 \mathrm{msec}$, whereas cells in the PoS lag the animal's head direction by $\sim 6 \mathrm{msec}$ (Blair and Sharp, 1995; Blair et al., 1997; Taube and Muller, 1997). The mean values from a time shift analysis using peak firing rate, range width, information content, and $\delta$ (for details, see Materials and Methods) for control and lesioned animals are shown in Table 3. $t$ tests revealed that AD HD cells from lesioned animals led the animal's head direction by a significantly greater amount than AD HD cells from intact animals for all but one of the four parameters (maximum peak firing rate: pooled $t_{(56)}=1.14 ; p>0.05$; minimum range width: pooled $t_{(56)}=3.51, p<0.05$; maximum information content: pooled $t_{(56)}=3.08, p<0.05 ; \delta$ : pooled $t_{(56)}=3.9, p<$ $0.05)$. To determine whether lesion size affected the temporal properties, a correlation between lesion size and each parameter was computed. None of the correlations differed significantly from zero. In addition, a $t$ test revealed no significant differences for any of the parameters between Groups A and B. These results suggest that the differences in $\delta$ and the time shift parameters between control and lesioned animals were not produced only by the more extensively lesioned animals.

Figure 8 shows composite graphs (see Materials and Methods) for the PoS-lesioned and intact animals. The graphs indicate that the degree of time shift that produces the optimal value for each parameter is greater for HD cells in PoS-lesioned animals than for HD cells in intact animals. The PoS lesion functions are all shifted to the right of the functions for intact animals. It also appears that the plots from lesioned animals are generally wider than those from intact animals. This result may be attributable to the fact that HD cells in PoS-lesioned animals have wider firing ranges than HD cells in intact animals, because previous analyses in intact animals have shown that cells with larger directional firing ranges have wider optimal shift functions than cells with smaller directional firing ranges (unpublished data).

\section{Cue card rotations}

A total of 31 Rotation series were conducted on 26 of the $31 \mathrm{HD}$ cells recorded in lesioned animals. A Rotation series was performed at least once on all 11 animals. Of the 31 Rotation series, 11 series were performed on HD cells whose response to cue card rotations had been measured at least once before. Ten series involved the simultaneous recording of two or three HD cells. In all of these sessions, the change in preferred firing direction exhibited by one cell was always within $12^{\circ}$ of the change observed in the other cell. This result is similar to findings reported from control animals and shows that HD cells from the same brain region shift in register with one another. This result implies that the appropriate measure for calculating the mean changes in preferred direction after environmental manipulation is not the number of cells but rather the number of cue card rotation manipulations.

Figure $9 B$ shows a distribution of the shifts in preferred firing direction in the 31 Rotation series. The histogram shows that the preferred directional shifts are more widely distributed compared with a similar graph constructed from data in control animals (Fig. 9A) and indicates that the cue card did not exert substantial control over the preferred firing directions of HD cells in lesioned animals. The mean absolute deviation between the shift in preferred firing direction from the Standard to Rotation session and the expected $90^{\circ}$ was $76.26 \pm 11.71^{\circ}$. This value differs significantly from the value $\left(15.20 \pm 2.86^{\circ}\right)$ reported in intact animals (unpooled $t_{(15)}=4.82 ; p<0.05$ ). However, a Rayleigh test (Batschelet, 1981) indicates that the distribution of shifts in the preferred firing direction is significantly different from a random distribution $\left(r_{(62)}=0.31 ; p<0.05\right)$. The nonrandomness of the distribution appears to result from the fact that the preferred firing direction of the cell more often shifted in the expected direction (37 times) than in the unexpected direction (24 times). This finding indicates that the cue card did exert some control over the preferred firing direction in lesioned animals, even if the degree of this control was lower than in intact animals. Figure $10 \mathrm{~A}$ is an example of an HD cell in a lesioned animal where the preferred direction shifted in the wrong direction when the cue card was rotated $90^{\circ}$ counterclockwise. Figure $10 B, C$ displays two cells recorded simultaneously that shifted the correct direction when the cue card was rotated away from the standard 


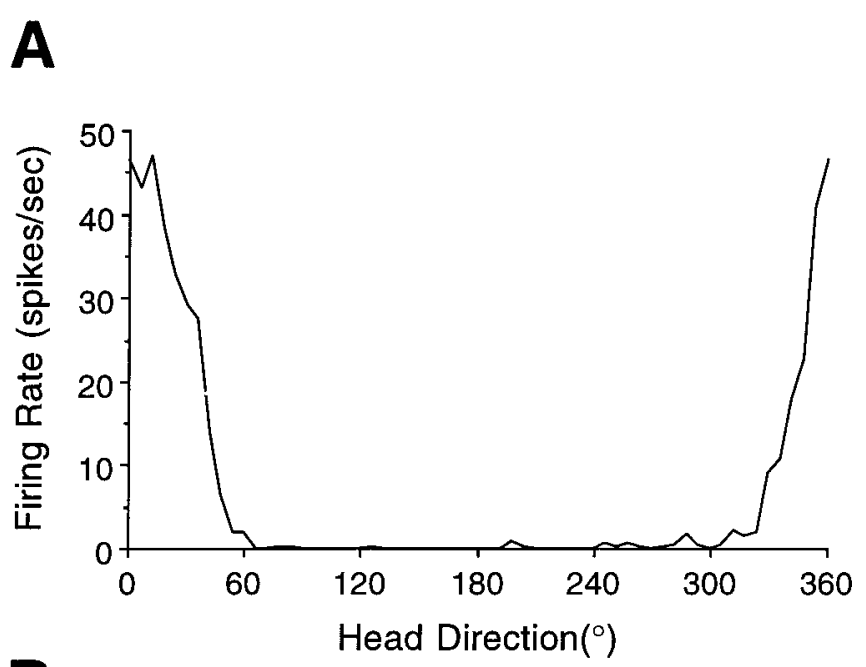

B

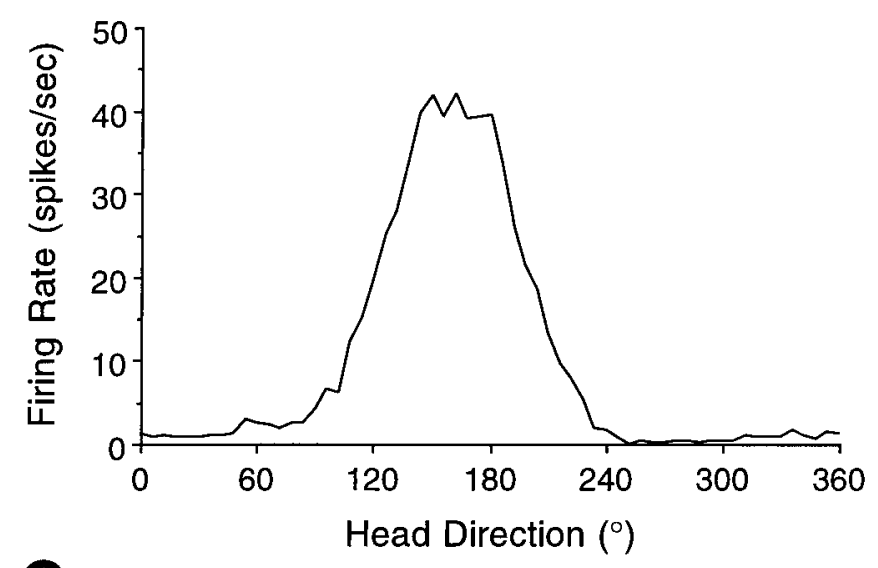

C

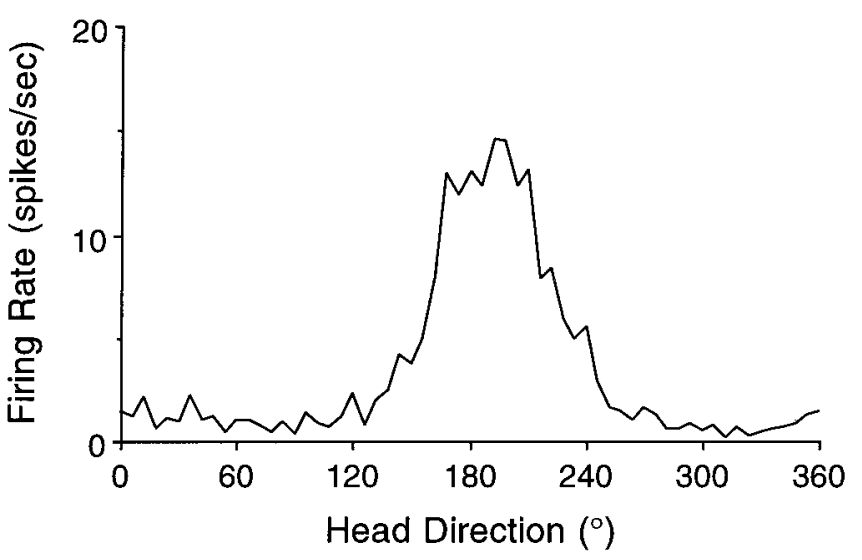

Figure 7. Firing rate versus $\mathrm{HD}$ plots of $\mathrm{AD} \mathrm{HD}$ cells from an intact animal $(A)$ and from PoS-lesioned animals $(B, C)$. Note that the directional firing ranges of the cells from the PoS-lesioned animals $(B, C)$ are larger than the directional firing range of the cell from the intact animal $(A)$.

position, but shifted the wrong direction when the cue card was returned to the standard position.

In the Standard 2 session, the preferred firing direction of HD cells in the PoS-lesioned animals did not usually return to its Standard 1 orientation. The mean absolute deviation between
Standard 1 and Standard 2 sessions was $65.61 \pm 10.58^{\circ}$. This value is significantly different from the mean value of $6.60 \pm 1.85^{\circ}$ in AD HD cells from control animals (unpooled $t_{(10)}=5.49 ; p<$ $0.05)$.

The stability of the preferred firing direction in repeated Standard sessions was further tested in five sessions in which a second Standard session was conducted immediately after another Standard session, without any intervening Rotation session. In these Standard-Standard sessions, all procedures were identical to a Standard-Rotation sequence, except that the cue card was not rotated. In particular, in between the two sessions the animal was removed from the cylinder, the floor paper was changed, and the animal was gently spun in the cardboard box before being returned to the cylinder. The mean absolute change in the preferred firing direction of the cell between the two Standard sessions was $85.2 \pm$ $29.1^{\circ}$ (range, $18-162^{\circ}$ ). This value is similar to the change in preferred firing direction that occurred when the cue card was rotated $\left(72.48 \pm 8.23^{\circ}\right)$. This result suggests that merely removing the animal and spinning it in the box (which presumably disorients it) is sufficient to induce a change in the preferred firing direction of the cell. The rotation of the cue card does not appear to increase the extent of shift in the preferred firing direction of the cell beyond these other factors.

Although there did not appear to be any relationship between lesion size and the degree to which the HD cells followed the cue card for a particular animal, a correlation $(r=-0.456)$ between lesion size and the absolute deviation of the HD cell shifts when the cue card was shifted to a rotated position was significantly different from zero (pooled $t_{(29)}=2.76 ; p<0.05$ ). However, this correlation was not in the expected direction and suggested that the preferred firing direction of a cell was more likely to follow the cue card in more extensively lesioned animals than in partially lesioned animals. The relationship between lesion size and absolute deviation when the cue card was returned to its standard position was not significant. A $t$ test comparing Group A with Group B confirmed the general pattern of the correlations. The preferred directions of HD cells in rats from Group A followed the cue card significantly more reliably when it was rotated from its standard position than preferred directions of HD cells in rats from Group B (pooled $\left.t_{(29)}=2.23 ; p<.05\right)$. When the cue card was returned to its standard position, HD cells in Group A rats did not follow the cue card any more or less reliably than HD cells in the four least lesioned animals.

In sum, these results show that the cue card was substantially less capable of exerting control over the preferred firing direction of AD HD cells in PoS-lesioned animals compared with intact animals. A loss of cue card stimulus control has also been observed after repeated disorientation of the animal when it is carried into and out of the recording room (Knierim et al., 1995). However, the extent of this reduction in cue control was substantially less than the loss of cue control reported here after PoS lesions.

\section{Cue card removals}

The stimulus control of cues other than the cue card was examined in seven sessions (four cells in four animals) in which the cue card was removed. The mean absolute change between the preferred firing direction in the Standard session and the No Cue Card session was $44.57 \pm 11.71^{\circ}$. This value is not significantly different from the value reported in AD HD cells in control animals: $73.2 \pm 29.1^{\circ}$ (Goodridge and Taube, 1995) (unpooled $t_{(7)}$ $=0.06 ; p>0.05)$. 
Table 3. Time-shift analysis after PoS lesions

\begin{tabular}{|c|c|c|c|c|c|}
\hline & $n^{a}$ & $\begin{array}{l}\text { Number of samples } \\
\text { shifted for maxi- } \\
\text { mum peak firing } \\
\text { rate }\end{array}$ & $\begin{array}{l}\text { Number of samples } \\
\text { shifted for mini- } \\
\text { mum range width }\end{array}$ & $\begin{array}{l}\text { Number of samples } \\
\text { shifted for maxi- } \\
\text { mum information } \\
\text { content }\end{array}$ & $\begin{array}{l}\text { Shift between } \\
\text { clockwise and } \\
\text { counterclockwise } \\
\text { functions }\left({ }^{\circ}\right)\end{array}$ \\
\hline \multicolumn{6}{|l|}{ Group } \\
\hline Control & 33 & $1.85 \pm 0.42$ & $1.27 \pm 0.26$ & $1.06 \pm 0.18$ & $4.91 \pm 0.92$ \\
\hline PoS lesions & 25 & $2.72 \pm 0.68$ & $3.12 \pm 0.50^{b}$ & $2.16 \pm 0.34^{b}$ & $11.69 \pm 1.59^{b}$ \\
\hline \multicolumn{6}{|c|}{ Correlation between lesion } \\
\hline size and parameter & & 0.009 & 0.223 & 0.284 & 0.11 \\
\hline
\end{tabular}

${ }^{a}$ All values of $n$ refer to the number of cells identified in the group, not the number of animals.

${ }^{b}$ Indicates significant $(p<0.05)$ pooled $t$ test relative to the control group.

\section{Intrasession drift}

Because the preferred directions of AD HD cells in PoS-lesioned animals did not maintain stability across different recording sessions, we also examined whether cells could maintain stability within a session. For all recording sessions $\geq 8 \mathrm{~min}$, we compared the preferred firing direction of the cell in the first and last $2 \mathrm{~min}$ of the session's first $8 \mathrm{~min}$. A difference in preferred firing direction of $>30^{\circ}$ occurred in 37 of 222 (16.7\%) sessions. Although this percentage may appear small, intrasession drifts of this magnitude are rarely observed in control animals. (Note: none of these 37 sessions were included in the analysis of parameters performed above, because these sessions either did not meet the isolation criteria described above or were not the first Standard session performed on a particular cell.) Figure $11 B$ shows the results from one of these cases, in which an 8 min Standard session is divided into four 2 min epochs. Note that the preferred firing direction of the cell did not drift in the same direction throughout the session. It initially drifted in the clockwise direction (decreasing head directions) and then drifted back in a counterclockwise direction. For comparison, an example of a control HD cell graphed in 2 min epochs is shown in Figure $11 \mathrm{~A}$.

\section{Novel environment}

Six cells in six animals were monitored as the rats walked from the cylinder to a novel environment consisting of a passageway and rectangle. This manipulation was intended to measure whether HD cells could maintain their preferred firing direction while the rat walks into a novel environment, an ability that presumably requires the use of idiothetic information and path integration (Gallistel, 1990; Taube and Burton, 1995). The absolute changes in the preferred firing direction of HD cells from the cylinder to the novel rectangle/passageway in the six sessions were $-15,-18$, $-30,+60,+84$, and $-90^{\circ}$ (positive values indicate counterclockwise shifts and negative values indicate clockwise shifts), with a mean absolute change of $44.6 \pm 13.5^{\circ}$. The larger three values cannot be attributed to the preferred directions shifting to remain in alignment with the salient cue in the rectangle because similar values were also obtained when comparing the preferred directions in the passageway alone, before the animal could view the cue card in the rectangle. Although the mean value is much larger than the mean value reported in control animals $\left(17.1 \pm 3.8^{\circ}\right)$ (Taube and Burton, 1995) (only animals recorded in the AD were included in this analysis), the two values are not significantly different using either an unpooled $t$ test $\left(t_{(6)}=1.93 ; p>0.05\right)$ or a Mann-Whitney test $\left(U_{(7,6)}=8 ; p>0.05\right)$. The failure to reach significance may be attributable to the small number of manipulations we conducted in the lesioned animals. However, there is a trend toward significance: the $p$ value for the $t$ test was $<0.07$.
Furthermore, it is noteworthy that three of the six shifts observed in lesioned animals were greater than any shifts observed in control animals; the maximum shift observed in intact animals was $30^{\circ}$. A pooled $t$ test does achieve significance $\left(t_{(11)}=2.5 ; p<\right.$ $.05)$, but this test requires that the variances of the two groups are the same. This assumption is probably not warranted $\left(F_{(6,7)}=\right.$ 10.88; $p<0.05)$.

Three of the six HD cells monitored as the animal entered the novel environment were from Group A rats, and three HD cells were from Group B animals. The mean shift in group A rats was $60^{\circ}$, and the mean shift in the Group B rats was $39^{\circ}$. Because of the low number of cases in each group, a statistical comparison between the two groups was unwarranted.

In sum, these results indicate that the PoS lesions may interfere somewhat with the degree to which HD cells can remain stable as the rat locomotes into a novel environment. For comparison, preliminary data show that both $\mathrm{PoS}$ and AD HD cells in hippocampal-lesioned animals exhibit large shifts (mean shift $=$ $94.7^{\circ}$ ) in the preferred firing direction when an animal locomotes from the familiar to a novel environment (Golob and Taube, 1996). This finding indicates that PoS lesions may interfere with accurate path integration in a manner similar to that of hippocampal lesions (also see Whishaw et al., 1997).

\section{DISCUSSION}

These experiments were designed to examine how the HD signal is generated in the brain. In particular, we examined the interaction between the AD and PoS by lesioning each structure and monitoring HD cell activity in the other region. Complete lesions of the AD abolished HD cell firing in the PoS, a finding that demonstrates that the $\mathrm{AD}$ is necessary for the presence of direction-specific activity in the PoS. In contrast, a large number of AD neurons remained direction-specific after PoS lesions, a result that indicates that the generation of direction-specific activity in the AD does not require the PoS. However, AD HD cells in PoS-lesioned animals exhibited three important differences from AD HD cells in intact animals. First, their directional firing range was significantly larger than the firing range of $\mathrm{AD} H D$ cells in intact animals. Second, their firing anticipated the animal's directional heading by $\sim 41 \mathrm{msec}$ rather than $25 \mathrm{msec}$, which is the value obtained from AD HD cells in control animals (Blair and Sharp, 1995; Blair et al., 1997; Taube and Muller, 1997). Third, their preferred firing direction was not reliably controlled by the position of the cue card. Instead, the cell's preferred firing direction shifted unpredictably after cue card rotations. 

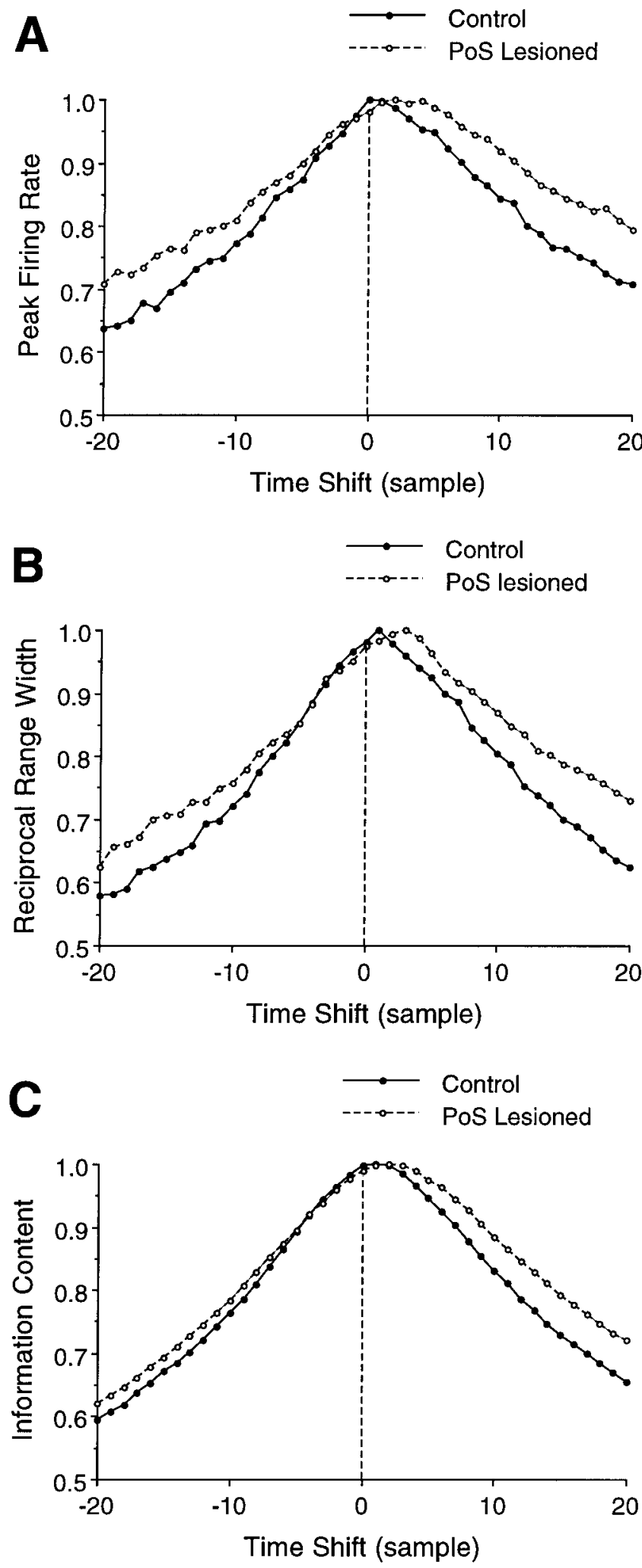

Figure 8. $A-C$, Composite graphs from PoS-lesioned and intact animals showing normalized peak firing rate $(A)$, normalized reciprocal range width $(B)$, and normalized information content $(C)$ as a function of the number of samples that the spike series was shifted relative to the head direction series. To facilitate comparison between graphs, the range width is shown as the reciprocal value. Note that for each parameter, the graph from PoS-lesioned animals is shifted to the right of the graph from intact animals, particularly around the peak.

\section{AD influence on the PoS}

A number of explanations could account for the elimination of direction-specific activity in PoS neurons after AD lesions. The simplest account is that PoS HD neurons in intact animals receive all necessary directional information through a direct projection from AD HD cells. Although this account is the most attractive explanation because there is ample anatomical evidence for a direct projection from AD to PoS (van Groen and Wyss, 1990c, 1995; Shibata, 1993b), it is currently unclear whether this projection originates from AD HD cells or from other nondirectional cells within the AD. An alternative explanation is that the $\mathrm{AD}$ projection to the PoS may serve to modulate the input from other brain areas, which themselves provide directional input to PoS HD neurons. For example, the AD projection may serve as a gating device that activates PoS neurons sufficiently so that they are sensitive to the directional input from other structures. The PoS receives major input from three other structures that could provide, in principle, this directional input: (1) the lateral dorsal thalamic nucleus (Thompson and Robertson, 1987; Van Groen and Wyss, 1992b), (2) the subiculum (Van Groen and Wyss, 1990c), and (3) the retrosplenial cortex (Van Groen and Wyss, 1990c, 1992a). However, neither lateral dorsal thalamic lesions (Golob et al., 1997) nor hippocampal lesions (Golob and Taube, 1997) disrupt the presence of HD cell discharge in the PoS. Because subicular activity is predominantly influenced by input from the hippocampus, these results suggest that neither lateral dorsal thalamic input nor subicular input is necessary for the generation of HD cell discharge in the PoS. Considering that the role of the retrosplenial cortex in PoS HD cell activity remains unexplored, we cannot exclude the possibility that the $\mathrm{AD}$ is influencing PoS HD activity through its connections with the retrosplenial cortex (Van Groen and Wyss, 1990c, 1992a; Shibata, 1993a). Nonetheless, findings to date suggest that the most parsimonious explanation for our data is that directionspecific firing is generated in the PoS because of the direct input from AD HD cells.

It is important to note that whatever route HD information is conveyed to the PoS, it is likely that $\mathrm{AD}$ directional information is not the only input received by PoS HD cells, because AD HD firing anticipates PoS HD firing by $\sim 30-40 \mathrm{msec}$ (averaged over the population of HD cells in each area) (Blair and Sharp, 1995; Blair et al., 1997; Taube and Muller, 1997). This time interval is longer than the $\sim 2-3 \mathrm{msec}$ required for information to be propagated monosynaptically from the $\mathrm{AD}$ to the $\mathrm{PoS}$ in the rat brain (assuming a 1-2 msec synaptic delay and a $50 \mathrm{~m} / \mathrm{sec}$ rate of axonal propagation). Thus, although the PoS probably receives directional input directly from $\mathrm{AD} \mathrm{HD}$ neurons, additional input onto PoS HD cells is likely required for them to lag AD HD cell firing by $30-40 \mathrm{msec}$.

\section{PoS influence on the AD}

If PoS HD activity is generated by input from AD HD cells, then it becomes important to determine what inputs are critical for generating direction-specific discharge in $\mathrm{AD} \mathrm{HD}$ cells. Our results indicate that $\mathrm{AD} \mathrm{HD}$ cell activity does not arise from a signal relayed back from the PoS, because HD cells could still be identified in the $\mathrm{AD}$ after PoS lesions. Although none of our PoS lesions were complete, AD HD cells were still identified in the two animals with at least $95 \%$ of the PoS lesioned, a result that suggests that the vast majority of the PoS was not necessary to sustain direction-specific discharge in the AD. Although the 5\% of PoS tissue remaining may be sufficient to support AD HD cell 

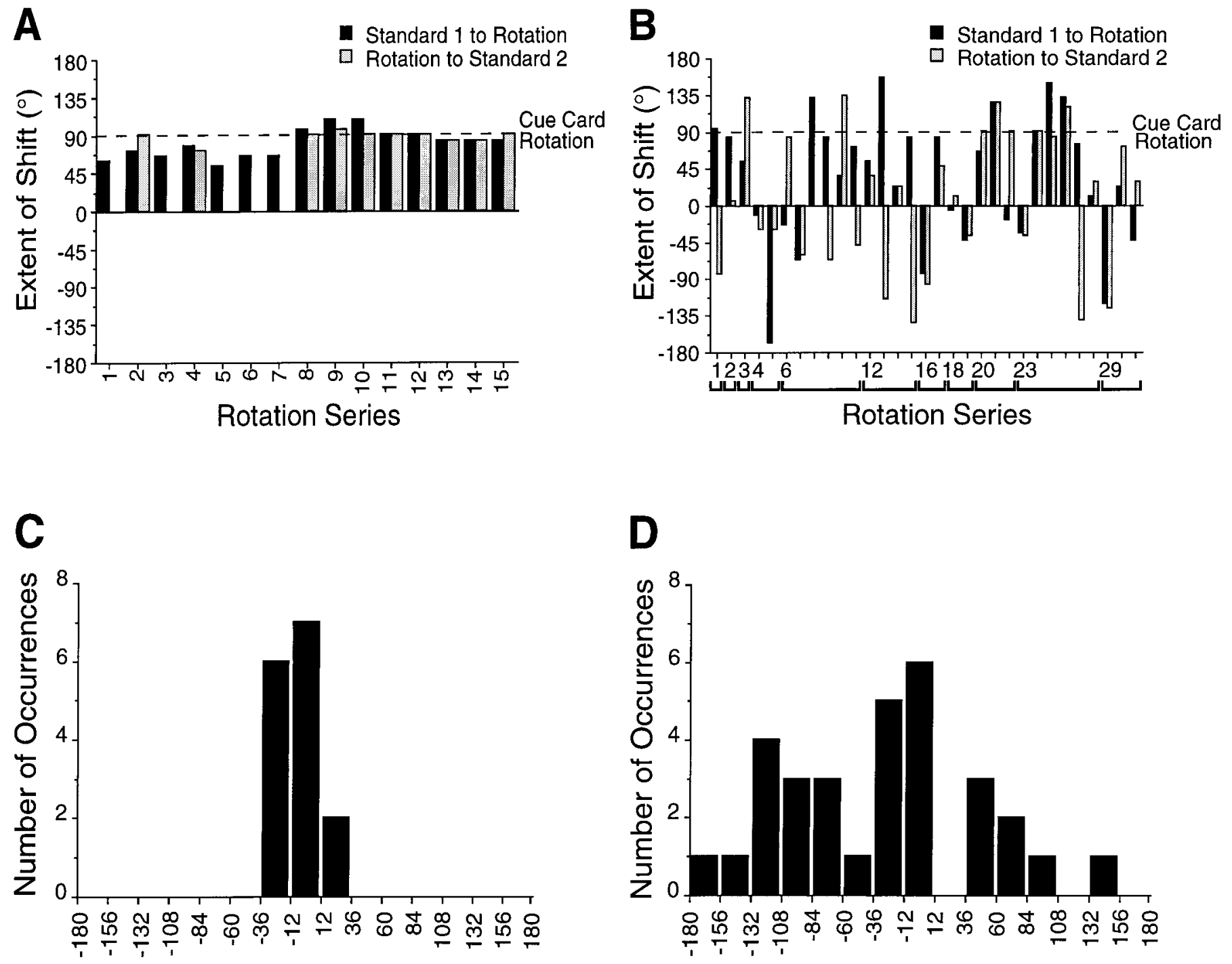

\section{Shift in Preferred Firing Direction $\left({ }^{\circ}\right)$}

\section{Shift in Preferred Firing Direction $\left({ }^{\circ}\right)$}

Figure 9. $A, B$, Distribution of shifts in the preferred firing direction from intact animals $(A)$ and PoS-lesioned animals $(B)$ during the Cue Card Rotation series. Abscissa plots the number of each Rotation Series, and the ordinate plots the extent of shift that the rotation produced in the preferred firing direction of the cell. Negative values along the ordinate indicate that the preferred firing direction of the cell shifted in the opposite direction from that of the cue card, whereas positive values indicate that the preferred firing of the cell shifted in the same direction as that of the cue card. The absence of light bars in rotation series 1, 3, 5, 6, and 7 is attributable to the fact that a Standard 2 session was not performed in these sequences. Each number shown on the abscissa represents a different rotation series. Brackets delineate rotation series that were all performed in the same animal. $C$, $D$, Histograms from intact animals $(C)$ and lesioned animals $(D)$ showing the variability of preferred firing direction shifts after the rotation of the cue card away from its standard position. Abscissa plots the deviation of the shift in preferred firing direction from the expected $90^{\circ}$. Negative values indicate that the preferred firing direction of the cell shifted $<90^{\circ}$. Positive values indicate that the preferred firing direction of the cell shifted by $>90^{\circ}$. Ordinate plots the number of occurrences observed for each shift category. Note the large variability of preferred firing direction shifts in PoS-lesioned animals relative to intact animals.

discharge, it seems more likely that HD cell discharge was sustained by other structures that project to the AD. Previous research shows that in addition to the PoS input, the AD receives major projections from three structures: (1) the lateral mammillary nucleus (Cruce, 1975; Hayakawa and Zyo, 1989; Shibata, 1992), (2) the retrosplenial cortex (van Groen and Wyss, 1992a), and (3) the reticular thalamus (Shibata, 1992; Gonzalo-Ruiz and Lieberman, 1995). The ventral presubiculum, which we did not lesion in this study, does not project to the AD (Van Groen and Wyss, 1990b) and thus can only indirectly provide AD neurons with directional information. As mentioned above, previous stud- ies have reported some HD cells in the retrosplenial cortex (Chen et al., 1994), and preliminary studies in our laboratory indicate that HD cells are also present in the lateral mammillary nuclei (Leonhard et al., 1996). Thus, either the retrosplenial cortex or the lateral mammillary nuclei may provide AD HD neurons with sufficient input for generating directional firing. Because no studies have examined the spatial and behavioral correlates of neurons in the reticular thalamus, further studies of this area are particularly warranted.

Although PoS input is not necessary for HD cell firing in the AD, it clearly influences AD HD neurons. PoS lesions increased 

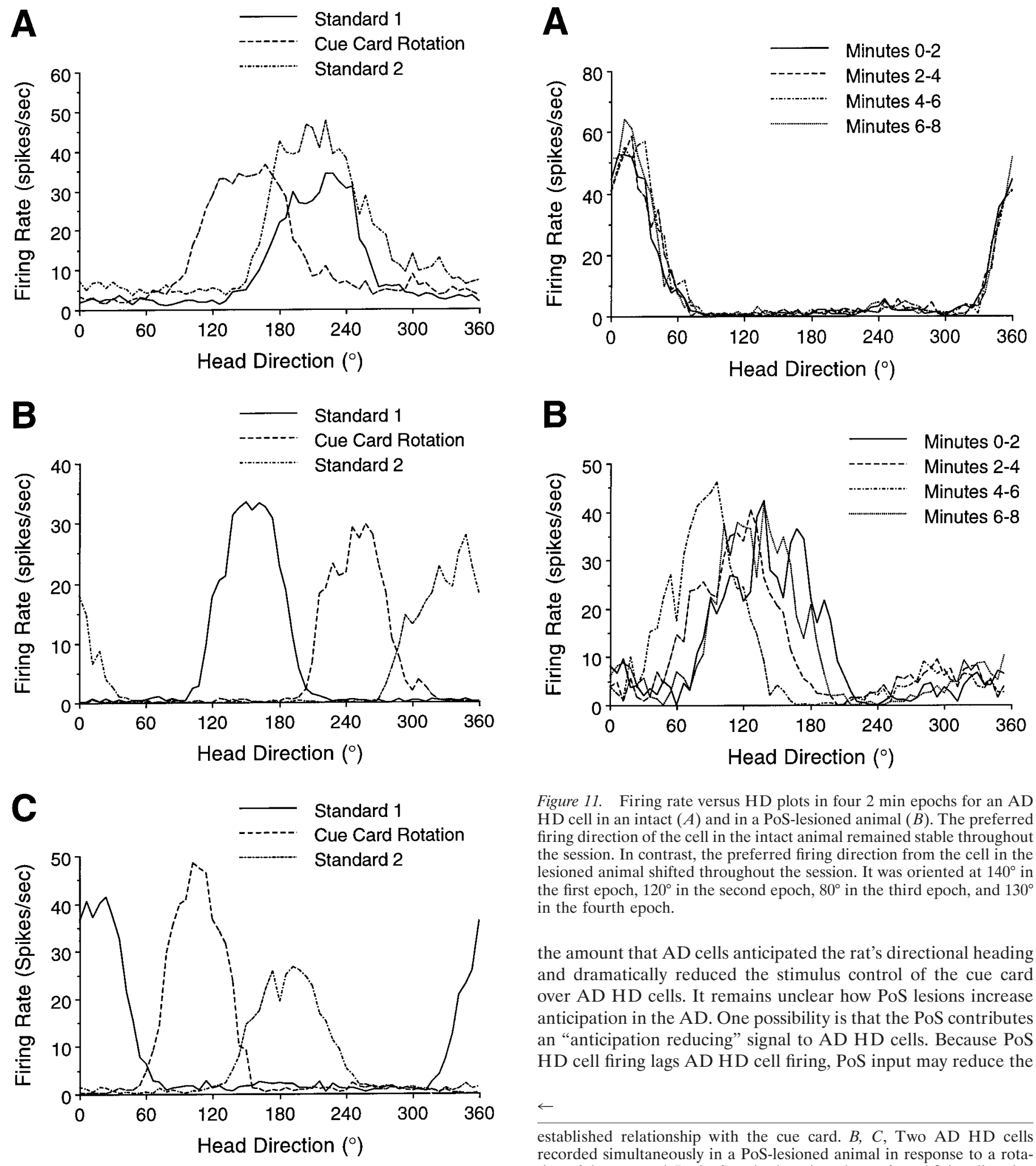

Figure 11. Firing rate versus $\mathrm{HD}$ plots in four 2 min epochs for an $\mathrm{AD}$ HD cell in an intact $(A)$ and in a PoS-lesioned animal $(B)$. The preferred firing direction of the cell in the intact animal remained stable throughout the session. In contrast, the preferred firing direction from the cell in the lesioned animal shifted throughout the session. It was oriented at $140^{\circ}$ in the first epoch, $120^{\circ}$ in the second epoch, $80^{\circ}$ in the third epoch, and $130^{\circ}$ in the fourth epoch.

the amount that AD cells anticipated the rat's directional heading and dramatically reduced the stimulus control of the cue card over AD HD cells. It remains unclear how PoS lesions increase anticipation in the AD. One possibility is that the PoS contributes an "anticipation reducing" signal to AD HD cells. Because PoS $\mathrm{HD}$ cell firing lags AD HD cell firing, PoS input may reduce the

established relationship with the cue card. $B, C$, Two AD HD cells recorded simultaneously in a PoS-lesioned animal in response to a rotation of the cue card. In the Standard session, the preferred firing direction of the first cell $(B)$ was oriented at $\sim 150^{\circ}$. After rotation of the cue card $90^{\circ}$ counterclockwise, the preferred firing direction of the cell shifted $96^{\circ}$ in the same direction. When the cue card was returned to its standard position, the preferred firing direction of the cell shifted $102^{\circ}$ in the opposite direction of the cue card. Thus, the preferred firing direction of the cell in the Standard 2 session was $\sim 168^{\circ}$ different from its orientation in the Standard 1 session. The preferred firing direction of the other simultaneously recorded cell $(C)$ shifted in register with the preferred firing direction of the cell in $B$ for each session of the cue rotation series. Cue Card Rotation series. $A$, An example of an AD HD cell in a PoS-lesioned animal which shifted its preferred firing direction in the direction opposite to that of the rotation of the cue card. In the Standard session, the preferred firing direction of the cell was oriented at $\sim 230^{\circ}$. After rotation of the cue card $90^{\circ}$ counterclockwise, the preferred firing direction of the cell shifted $66^{\circ}$ clockwise. When the cue card was rotated clockwise and returned to its standard position, the preferred firing direction of the cell shifted $60^{\circ}$ counterclockwise to return to its originally 
extent of anticipation in the AD. In addition, lateral mammillary HD cell firing appears to anticipate the animal's directional heading by a larger amount than AD HD cells (Leonhard et al., 1996). Thus, in the absence of the PoS, AD HD cells may be more heavily influenced by the anticipatory signal in the lateral mammillary area. Because the PoS projects to the lateral mammillary nuclei (Allen and Hopkins, 1989), it is also possible that PoS lesions altered the firing properties of lateral mammillary HD cells in a way that increased the anticipation of AD HD cells.

It is equally unclear how PoS lesions disrupt visual landmarkbased cue control in the AD. One possibility is that the PoS may transmit visual information directly to AD HD cells. Because the preferred firing direction of PoS HD cells also shifts in response to the position of visual cues, PoS HD cells may transfer this sensitivity to AD HD cells. There are at least four potential pathways by which visual information may be conveyed to the PoS and in turn to the AD. First, although not very dense, the PoS receives direct projections from the visual cortex (Vogt and Miller, 1983). Second, the PoS receives projections from the lateral dorsal nucleus (Van Groen and Wyss, 1990c, 1992b), which in turn receives information from the superior colliculus, the primary projection site for retinal ganglion cells in the rat (Thompson and Robertson, 1987). Third, the PoS may receive visual information from the retrosplenial cortex (Van Groen and Wyss, 1990a,c, 1992a), which can receive visual information from the posterior parietal (Vogt, 1985) or visual cortices (Vogt and Miller, 1983; Van Groen and Wyss, 1990c, 1992a). Fourth, the PoS may receive visual information from the subiculum, which in turn can receive visual information from the temporal cortex via the hippocampus (for review, see Amaral and Witter, 1995). The latter two pathways may be analogous to the "where" and "what" pathways described by Mishkin et al. (1983) in primates.

Previous research suggests that the lateral dorsal and temporal lobe pathways are not critical for landmark control in PoS because neither hippocampal nor lateral dorsal thalamic lesions disrupt the control of the cue card over the preferred firing direction of PoS HD cells (Golob and Taube, 1997; Golob et al., 1997). Thus, if the AD receives its visual information from PoS HD cells, it is unlikely to arise from the lateral dorsal thalamus and temporal lobe pathways. Instead, the projections from the retrosplenial cortex and/or the visual cortex presumably provide the critical visual information to the PoS. In principle, it is possible that the AD receives visual information via direct projections from the retrosplenial cortex (Hayakawa and Zyo, 1989). However, because the PoS lesions disrupted AD cue control while leaving the retrosplenial cortex to $\mathrm{AD}$ pathway intact, the direct transmission of visual information from the retrosplenial cortex to the AD appears to require PoS involvement. Nonetheless, the direct retrosplenial to AD pathway may still convey some residual spatial information about the cue card independently of PoS involvement, only because our results showed that the cue card still retained some influence over the preferred directions in many cases (e.g., see the Standard 1 to Rotation session for rotation series 1, 2, 9, 11, 15, 17, 24, 27 in Fig. 9B).

Rather than directly providing AD with all necessary visual information, the primary role of the PoS may be to modulate or activate the retrosplenial cortex, which itself conveys the visual information to the $\mathrm{AD}$. In addition to projecting to the $\mathrm{AD}$, the retrosplenial cortex receives direct projections from the PoS (Van Groen and Wyss, 1990a,c, 1992a). The lateral mammillary nuclei also receive projections from the PoS (Allen and Hopkins, 1989) and project to the AD (Shibata, 1992), but they are a less likely candidate for transferring visual information to the AD because the retrosplenial cortex is more closely connected with both visual and multi-modal cortical regions (Vogt and Miller, 1983; Vogt, 1985; Van Groen and Wyss, 1990c, 1992a) than the lateral mammillary nuclei, and the lateral mammillary nuclei are not believed to contribute in a major way to visual information processing. Taken together, because of its reciprocal connections with PoS, $\mathrm{AD}$, and visual cortical areas, and because hippocampal and LD lesions do not produce significant changes in HD firing, the retrosplenial cortex seems an important structure for explaining how PoS lesions disrupted cue control in the AD. Furthermore, the retrosplenial cortex and parietal pathway may be the primary source of visual cue information to the head direction circuit.

After PoS lesions, the preferred firing direction of AD HD cells usually maintained stability within single recording sessions. Thus, although PoS lesions dramatically reduced the intersession stability of the preferred firing direction of the cell, they did not eliminate the intrasession stability of the cells. This finding suggests that responsiveness to the position of environmental cues is not required for neurons to exhibit direction-specific discharge. This result provides support for the notion proposed by several investigators that the establishment and maintenance of the preferred firing direction are achieved by distinct mechanisms (McNaughton et al., 1991, 1995; Redish et al., 1996). According to these theories, the initial preferred firing direction of the cell is determined by environmental cues, but the update of that preferred orientation over short periods of time depends on the animal's ability to track its own movements, rather than to monitor environmental cues.

\section{Computational models}

A number of theories and computational models have recently been proposed to account for HD cell firing (Blair and Sharp, 1995; McNaughton et al., 1995; Skaggs et al., 1995; Blair, 1996; Redish et al., 1996; Zhang, 1996). Each model postulates a slightly different type of interaction between AD and PoS neurons. The models proposed by Blair and Sharp (1995) and Redish et al. (1996) involve extensive two-way interaction between HD cells in both structures. In these models, AD neurons convey information to PoS cells concerning the animal's future directional heading and thus allow these cells to update their HD. AD HD cells in the models in turn compute future directional heading by combining a current HD signal from the PoS with information about the animal's current angular head velocity. These models, however, cannot account for the presence of directionspecific discharge in the AD after PoS lesions, because in the models the PoS is the only structure conveying information to AD concerning the animal's current head direction.

In contrast to these models, Zhang's model (1996) does not suggest any interaction between the AD and PoS. Directionspecific discharge in each structure arises independently of input from the other structure. Thus, the finding that AD lesions eliminate HD cell firing in the PoS suggests that this model needs to be modified. Furthermore, the increase in the AD's anticipation of head direction after PoS lesions is difficult to account for using Zhang's model, because in the model the AD develops this characteristic independently. Unfortunately for all of these models, our data suggest that although there is some interdependence of HD cell firing between the two structures, there is not complete interdependence. Although AD lesions abolish HD cell firing in the PoS, lesions of the PoS only partially alter HD cell firing in the AD. 


\section{REFERENCES}

Allen GV, Hopkins DA (1989) Mamillary body in the rat: topography and synaptology of projections from the subicular complex, prefrontal cortex, and midbrain tegmentum. J Comp Neurosci 286:311-336.

Amaral DG, Witter MP (1995) Hippocampal formation. In: The rat nervous system, Ed 2 (Paxinos G, ed), pp 443-493. San Diego: Academic.

Batschelet E (1981) Circular statistics in biology. London: Academic.

Blackstad TW (1956) Commissural connections of the hippocampal region in the rat, with special reference to their mode of termination. J Comp Neurol 105:417-537.

Blair HT (1996) A thalamocortical circuit for computing directional heading in the rat. In: Advances in neural information processing systems, Vol 8 (Touretzky DS, Moser MC, Hasselmo ME, eds). Cambridge, MA: MIT.

Blair HT, Sharp PE (1995) Anticipatory head direction signals in the anterior thalamus: evidence for a thalamocortical circuit that integrates angular head velocity to compute head direction. J Neurosci 15:6260-6270.

Blair HT, Lipscomb BW, Sharp PE (1997) Anticipatory time interval of head-direction cells in the anterior thalamus of the rat: implications for path integration in the head-direction circuit. J Neurophysiol 78:145159.

Chen LL, Lin L, Barnes CA, McNaughton BL (1994) Head direction cells in the rat posterior cortex I: anatomical distributions and behavioral modulation. Exp Brain Res 101:8-23.

Cruce JAF (1975) An autoradiographic study of the projections of the mammillothalamic tract in the rat. Brain Res 85:211-219.

Gallistel CR (1990) The organization of learning. Cambridge, MA: MIT.

Golob EJ, Taube JS (1996) Head direction cells are less responsive to idiothetic cues in rats with hippocampal lesions. Soc Neurosci Abstr 22:1873.

Golob EJ, Taube JS (1997) Head direction cells and episodic spatial information in rats without a hippocampus. Proc Natl Acad Sci USA 94:7645-7650.

Golob EJ, Wolk DS, Taube JS (1997) Recordings of postsubicular head direction cells following lesions of the lateral dorsal thalamic nucleus. Brain Res, in press.

Gonzalo-Ruiz A, Lieberman AR (1995) Topographic organization of projections from the thalamic reticular nucleus to the anterior thalamic nuclei in the rat. Brain Res Bull 37:17-35.

Goodridge JP, Taube JS (1993) Lesions of the anterior thalamic nucleus disrupt head direction cell firing in the dorsal presubiculum. Soc Neurosci Abstr 19:796.

Goodridge JP, Taube JS (1994) The effect of lesions of the postsubiculum on head direction cell firing in the anterior thalamic nuclei. Soc Neurosci Abstr 20:805.

Goodridge JP, Taube JS (1995) Preferential use of the landmark navigational system by head direction cells in rats. Behav Neurosci 109:49-61.

Haug F-MS (1976) Sulfide silver pattern and cytoarchitectonics of parahippocampal areas in the rat. Adv Anat Embryol Cell Biol 52:7-73.

Hayakawa T, Zyo K (1989) Retrograde double-labeling study of the mammillothalamic and the mammillotegmental projections in the rat. J Comp Neurol 284:1-11.

Knierim JJ, Kudrimoti HS, McNaughton BL (1995) Place cells, head direction cells, and the learning of landmark stability. J Neurosci 15:1648-1659.

Kubie JL (1984) A drivable bundle of microwires for collecting singleunit data from freely moving rats. Physiol Behav 32:115-118.

Leonhard CL, Stackman RW, Taube JS (1996) Head direction cells recorded from the lateral mammillary nuclei in rats. Soc Neurosci Abstr 22:1873.

McNaughton BL, Chen LL, Markus EJ (1991) "Dead reckoning," landmark learning, and the sense of direction: a neurophysiological and computational hypothesis. J Cogit Neurosci 3:190-202.

McNaughton BL, Knierim JJ, Wilson MA (1995) Vector encoding and the vestibular foundations of spatial cognition: neurophysiological and computational mechanisms. In: The cognitive neurosciences (Gazzaniga $\mathrm{M}$, ed), pp 585-595. Cambridge, MA: MIT.

Mishkin M, Ungerleider GL, Mack K (1983) Object vision and spatial vision: two cortical pathways. Trends Neurosci 6:414-417.
Mizumori SJY, Williams JD (1993) Directionally selective mnemonic properties of neurons in the lateral dorsal nucleus of the thalamus of rats. J Neurosci 13:4015-4028.

Paxinos G, Watson C (1986) The rat brain stereotaxic coordinates. New York: Academic.

Ranck Jr JB (1984) Head-direction cells in the deep cell layers of dorsal presubiculum in freely moving rats. Soc Neurosci Abstr 10:599.

Redish AD, Elga AN, Touretzky DS (1996) A coupled attractor model of the rodent head direction system. Network 7:671-685.

Shibata H (1992) Topographic organization of subcortical projections to the anterior thalamic nuclei in the rat. J Comp Neurol 323:117-127.

Shibata H (1993a) Efferent projections from the anterior thalamic nuclei to the cingulate cortex in the rat. J Comp Neurol 330:533-542.

Shibata H (1993b) Direct projections from the anterior thalamic nuclei to the retrohippocampal region in the rat. J Comp Neurol 337:431-445.

Skaggs WE, McNaughton BL, Gothard KM, Markus EJ (1993) An information-theoretic approach to deciphering the hippocampal code. In: Advances in neural information processing 5 (Hanson SJ, Cowan JD, Giles CL, eds) pp 1030-1037. San Mateo, CA: Morgan Kaufmann.

Skaggs WE, Knierim JJ, Kudrimoti HS, McNaughton BL (1995) A model of the neural basis of the rat's sense of direction. In: Advances in neural information processing systems, Vol 7 (Touretzky DS, Tesauro G, Leen TK, eds), pp 173-180. Cambridge, MA: MIT.

Taube JS (1995) Head direction cells recorded in the anterior thalamic nuclei of freely moving rats. J Neurosci 15:70-86.

Taube JS, Burton H (1995) Head direction cell activity monitored in a novel environment and a conflict situation. J Neurophysiol 74:1953-1957.

Taube JS, Muller RU (1997) Comparison of head direction cell activity in the postsubiculum and anterior thalamus of freely moving rats. Hippocampus, in press.

Taube JS, Muller RU, Ranck JB (1990a) Head-direction cells recorded from the postsubiculum in freely moving rats. I. Description and quantitative analysis. J Neurosci 10:420-435.

Taube JS, Muller RU, Ranck JB (1990b) Head direction cells recorded from the postsubiculum in freely moving rats. II. Effects of environmental manipulations. J Neurosci 10:436-447.

Thompson SM, Robertson TT (1987) Organization of subcortical pathways for sensory projections to the limbic cortex. II. Afferent projections to the thalamic lateral dorsal nucleus in the rat. J Comp Neurol 265:189-202.

Van Groen T, Wyss JM (1990a) Connections of the retrosplenial granular a cortex in the rat. J Comp Neurol 300:593-606.

Van Groen T, Wyss JM (1990b) The connections of presubiculum and parasubiculum in the rat. Brain Res 528:227-245.

Van Groen T, Wyss JM (1990c) The postsubicular cortex in the rat: characterization of the fourth region of the subicular cortex and its connections. Brain Res 529:165-177.

Van Groen T, Wyss JM (1992a) Connections of the retrosplenial dysgranular cortex in the rat. J Comp Neurol 315:200-216.

Van Groen T, Wyss JM (1992b) Projections from the laterodorsal nucleus of the thalamus to the limbic and visual cortices in the rat. J Comp Neurol 324:427-448.

Van Groen T, Wyss JM (1995) Projections from the anterodorsal and anteroventral nucleus of the thalamus to the limbic cortex in the rat. J Comp Neurol 358:584-604.

Vogt BA (1985) Cingulate cortex. In: Cerebral cortex, 4: association and auditory cortices (Peters A, Jones EG, eds), pp 89-149. New York: Plenum.

Vogt BA, Miller MW (1983) Cortical connections between rat cingulate cortex and visual, motor, and postsubicular cortices. J Comp Neurol 216:192-210.

Whishaw IQ, McKenna JE, Maaswinkel H (1997) Hippocampal lesions and path integration. Curr Opin Neurobiol 7:228-234.

Wiener SI (1993) Spatial and behavioral correlates of striatal neurons in rats performing a self-initiated navigational task. J Neurosci 13:3802-3817.

Witter MP, Groenwegen JJ, Lopes Da Silva FH, Lohman AH (1989) Functional organisation of the extrinsic and intrinsic circuitry of the parahippocampal region. Prog Neurobiol 33:161-253.

Zhang K (1996) Representation of spatial orientation by the intrinsic dynamics of the head direction cell ensemble. J Neurosci 16:21122126. 